University of Rhode Island

DigitalCommons@URI

Civil \& Environmental Engineering Faculty

Publications

Civil \& Environmental Engineering

2019

Fracture Response of Metallic Particulate-reinforced

Cementitious Composites: Insights from Experiments and

Multiscale Numerical Simulations

Sumeru Nayak

University of Rhode Island

N.M. Anoop Krishnan

Sumanta Das

University of Rhode Island, sumanta_das@uri.edu

Follow this and additional works at: https://digitalcommons.uri.edu/cve_facpubs

The University of Rhode Island Faculty have made this article openly available.

Please let us know how Open Access to this research benefits you.

This is a pre-publication author manuscript of the final, published article.

Terms of Use

This article is made available under the terms and conditions applicable towards Open Access

Policy Articles, as set forth in our Terms of Use.

Citation/Publisher Attribution

Nayak, S., Krishnan, N.M. A., \& Das, S. (2019). Fracture Response of Metallic Particulate-reinforced Cementitious Composites: Insights from Experiments and Multiscale Numerical Simulations. Cement and Concrete Composites, 97, 154-165. doi: 10.1016/j.cemconcomp.2018.12.026

Available at: https://doi.org/10.1016/j.cemconcomp.2018.12.026

This Article is brought to you for free and open access by the Civil \& Environmental Engineering at DigitalCommons@URI. It has been accepted for inclusion in Civil \& Environmental Engineering Faculty Publications by an authorized administrator of DigitalCommons@URI. For more information, please contact digitalcommonsgroup@uri.edu. 


\title{
Fracture Response of Metallic Particulate-reinforced Cementitious Composites: Insights from Experiments and Multiscale Numerical Simulations
}

\author{
Sumeru Nayak ${ }^{1}$, N. M. Anoop Krishnan ${ }^{2}$, Sumanta Das ${ }^{3}$ \\ ${ }^{1}$ Graduate Student, Civil and Environmental Engineering, University of Rhode Island, Kingston, \\ RI 02881, United States \\ ${ }^{2}$ Assistant Professor, Department of Civil Engineering, Indian Institute of Technology Delhi, \\ Hauz Khas, New Delhi-110016, India \\ ${ }^{3 *}$ Assistant Professor, Civil and Environmental Engineering, University of Rhode Island, \\ Kingston, RI 02881, United States, Email: sumanta_das@uri.edu (corresponding author)
}

\begin{abstract}
This paper presents an experimental and numerical investigation into the fracture response of mortars containing up to $30 \%$ waste iron powder by volume as OPC-replacement. The iron powdermodified mortars demonstrate significantly improved strength and fracture properties as compared to the control mortars due to presence of elongated iron particulates in the powder. With a view to develop a predictive tool towards materials design of such particulate-reinforced systems, fracture responses of iron powder-modified mortars are simulated using a multiscale numerical approach. The approach implements multi-scale numerical homogenization involving cohesive zone-based damage at the matrix-inclusion interface and isotropic damage in the matrix to obtain composite constitutive response and fracture energy. Consequently, these results serve as input to macro-scale XFEM-based three-point-bend simulations of notched mortar beams. The simulated macroscopic fracture behavior exhibit excellent match with the experimental results. Thus, the numerical approach links the material microstructure to macroscopic fracture parameters facilitating microstructure-guided material design.
\end{abstract}

Keywords: Iron powder; Fracture toughness; Two-parameter fracture model; Multi-scale numerical simulations; Finite element method 


\section{INTRODUCTION}

Concrete, being one of the most versatile building materials, is widely used all over the world. One of the major causes of concern related to manufacturing of cement is its poor sustainability credentials [1,2]. Manufacturing process of cement is considered to be a major contributor to global $\mathrm{CO}_{2}$-emissions $[3,4]$. On the other hand, another concern regarding the use of cementitious materials has been their inherent brittleness and poor fracture resistance [5,6]. The central idea of this paper stems from addressing the abovementioned concerns towards obtaining a material that reduces $\mathrm{CO}_{2}$-emissions as well as provides improved resistance to crack growth and developing a numerical tool to design such materials comprehensively.

Several modified and alternative cementitious materials such as supplementary cementitious materials [7,8], alkali-activated binders [9-11], and carbon-negative binders [12-14] have been widely studied over the past few decades to improve sustainability credentials of concrete. On the other hand, several particulate reinforced composites have shown improved toughness [15,16]. Applications of carbon based nanoparticles in polymer matrices [17-20], oxides or nitrides in metal matrix composites [21,22], metallic particles in ceramics $[23,24]$ and nano-clay in polymers $[25,26]$ have served as particulate reinforcements with beneficial fracture properties. The fracture behavior of brittle matrices has shown significant improvements when rigid inclusions are incorporated [27,28]. The issue of poor fracture response of quasibrittle cementitious composites has been addressed incorporating steel fibers [29,30], glass fibers [31,32], carbon fibers [33,34], wollastonite [35,36], and textile reinforcement [37,38] in the cementitious matrix. Use of metallic waste particle-incorporation in heavy concrete has also been experimentally evaluated [3941]. This paper incorporates waste iron powder as cement-replacement to address the concern related to poor sustainability credentials of cementitious materials by replacing cement partially thereby reducing the carbon-footprint of concrete. This waste iron powder is an industrial byproduct and it is generated in large quantities in electric-arc furnace (EAF) steel production facilities and shot-blasting operations of structural steel sections. Traditionally, this waste iron powder is landfilled since it is not economically feasible to recycle such waste materials. Several million tons of such waste product is being landfilled all over the world. Hence, use of such waste material in concrete as large volume cement-replacement would provide significant environmental benefit. In addition to the potential sustainability benefit, the elongated iron particulates in iron powder $[14,42,43]$ are likely to contribute towards improved crack-bridging mechanism and enhanced fracture response of mortars which are explored in detail in this study using three-point-bend test on notched mortar beams coupled with digital image correlation (DIC) [14,44-46].

Another important aspect of this study is to develop a predictive tool towards the material design of such inclusion-modified cementitious systems. Accurate prediction of constitutive relationship and fracture response in these systems necessitates a reliable technique that is capable of handling more than just the 
volume fraction of component phases. The effective properties of cementitious materials have been predicted using various analytical homogenization techniques [47-49]. Presence of closed form solutions and ease of analysis make these techniques very popular. However, these techniques are incapable to predict the post-peak response in many cases and are proved to be insufficient when dealing with phases with significant contrast in stiffness [50,51]. In recent past, computational techniques have been implemented [51,53-55] for improved accuracy. Lattice approach involving discrete elements have been used for mesoscale simulations [56,57]. However, applicability of such technique is limited when large deformations are considered [57,58]. Finite element method has been proved to be very efficient under such scenario [58].

Herein, exploiting the superiority of finite element methods [58], we implement a multiscale numerical framework to predict the fracture-response of iron-powder incorporated mortars. Numerical homogenization is performed at two different interactive length-scales to obtain effective constitutive response and fracture energy of iron powder-incorporated mortars. The numerical homogenization approach incorporates interfacial debonding at the matrix-inclusion interface using cohesive zone model (CZM) [59-61] and implements isotropic damage [62-64] in the matrix to simulate the composite postpeak response. In order to validate the multiscale numerical approach, macro-scale simulations for threepoint-bend test of notched mortar beams are performed using extended finite element method (XFEM). The macro-model imports composite material properties obtained from multi-scale numerical homogenization as input, incorporates a maximum principal stress-based crack initiation criteria and a bilinear traction separation law coupled with concrete damage plasticity (CDP) [65-67] for propagation of crack to obtain macro-scale fracture parameters which are validated against experimental values obtained from DIC. Overall, the present study intends to investigate the influence of iron powder incorporation in the mortars as cement-replacement and demonstrate a multi-scale numerical approach to predict macroscopic fracture response of such cementitious composites facilitating microstructure-guided material design.

\section{EXPERIMENTAL PROGRAM}

\subsection{Materials and mixture proportions}

The cement used for the experiments on mortar is commercially available Type I/II ordinary Portland cement. The chemical composition of the oxides of each element in the aforementioned OPC conforming to ASTM C150 is mentioned in Table 1.

Table 1. Chemical composition of oxides of each element in OPC (\%)

\begin{tabular}{lccccccccc}
\hline Element & $\mathbf{S i}$ & $\mathbf{A l}$ & $\mathbf{F e}$ & $\mathbf{C a}$ & $\mathbf{M g}$ & $\mathbf{S}$ & $\mathbf{N a}$ & $\mathbf{K}$ & Others \\
\hline Oxide\% & 21 & 3.61 & 3.47 & 63 & 3.26 & 3.04 & 0.16 & 0.36 & 2.13 \\
\hline
\end{tabular}


Metallic waste iron powder is obtained from industrial shot-blasting facility in Phoenix, AZ. The iron powder consists of $88 \% \mathrm{Fe}$ and atmospheric oxidation introduces $10 \%$ oxygen into it. Traces of $\mathrm{Cu}, \mathrm{Mn}$ and $\mathrm{Ca}$ are also present. The sand used in the mortar has a $\mathrm{d}_{50}$ of $600 \mu \mathrm{m}$ while that of iron powder is 19 $\mu \mathrm{m}$. The particle size distributions of OPC, sand and iron powder, obtained from laser diffraction analysis, are shown in Figure 1.

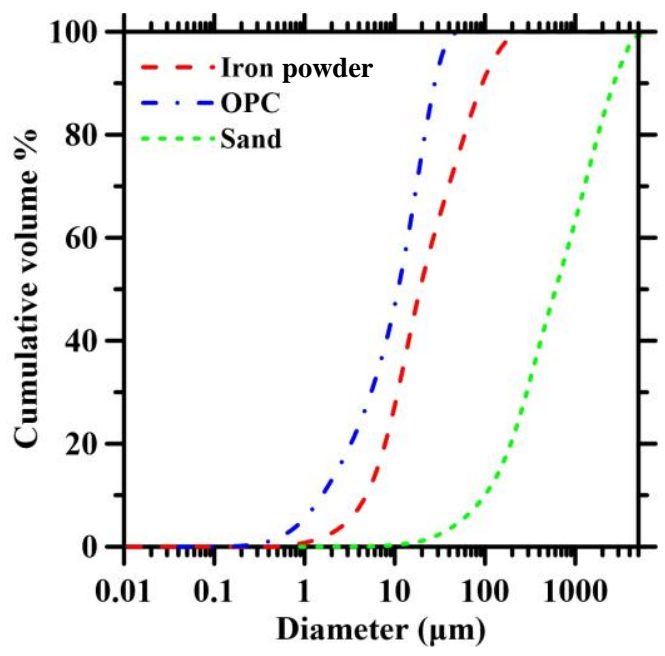

Figure 1. Particle size distribution of OPC, Iron powder and sand.

Four different mortar mixtures were prepared with by replacing 0\% (control mortar), 10\%, 20\%, and 30\% of OPC by volume. Other mix design parameters for all the mortars were similar with a mass-based watercement ratio of 0.5 and a constant sand volume of $50 \%$ in the mortar. This study does not consider iron powder content higher than $30 \%$ as cement-replacement since the mixtures with iron powder content higher than $30 \%$ do not show desirable rheological properties. While the flexural strength tests used four replicate prismatic beams of size 250 (length) x 50 (width) x 50 (depth) $\mathrm{mm}$ for each mixture, four replicate notched beams of size 330 (length) x 25 (width) x 76 (depth) mm were used for each mixture to evaluate fracture response. For compressive strength test, $50 \mathrm{~mm}$ cubes were cast. All the beams and cubes were cast and were demolded after 24 hours followed by exposure to a moist environment with $\mathrm{RH}>98 \%$ at a temperature of $23 \pm 2{ }^{\circ} \mathrm{C}$ for curing till the desired age of testing. For micro-structural examination, companion paste samples (iron powder in cement paste) were cast for each of the mixtures.

\subsection{Compressive and Flexural Strength Evaluation}

The 28-day compressive strengths were determined according to ASTM C109 and the flexural strengths were obtained after 28 days according to ASTM C293/C293M-10. The three-point-bend specimens of size 
$250 \times 50 \times 50 \mathrm{~mm}$ were supported with a span of $200 \mathrm{~mm}$ and were centrally loaded at a constant displacement rate of $0.004 \mathrm{~mm} / \mathrm{s}$.

\subsection{Three-point bend test coupled with Digital Image Correlation (DIC) for evaluation of fracture}

\section{behavior}

For evaluation of fracture behavior, three-point-bend tests were performed on notched mortar beams of size 330 (length) x 76 (depth) x $25 \mathrm{~mm}$ (width) with a span of $304 \mathrm{~mm}$ and notch depth of $19 \mathrm{~mm}$ as shown in Figure 2. For each mixture, four replicate beam specimens were tested. A closed loop testing machine was employed under crack mouth opening displacement (CMOD)-controlled mode where the CMOD was measured by a clip gauge. An initial load control mode was first employed up to a load of $100 \mathrm{~N}$ beyond which CMOD-controlled mode was initiated. A CMOD value of $0.2 \mathrm{~mm}$ marked the termination point of the test. The above-mentioned three-point-bend test was coupled with digital image correlation (DIC) method for direct measurement of crack length and fracture properties. DIC is a speckle-tracking noncontact method to obtain displacement and strain fields on the specimen surface $[14,45,46,68,69]$. The surfaces of the specimens were first painted white and then random black speckles were made on the white surface using a black spray-paint to achieve a good contrast. During the test, the specimen surface was imaged every 5 seconds by a charge-coupled device camera (CCD). After the test, the images were correlated and a rectangular area of $120 \times 60 \mathrm{~mm}$ above the notch (as shown in Figure 2) was analyzed to obtain the displacement fields using VIC-2D software ${ }^{\mathrm{TM}}$ [70]. The displacement fields, thus obtained from DIC, were used to obtain the fracture properties (fracture toughness and critical crack tip opening displacement) as detailed later in this paper.

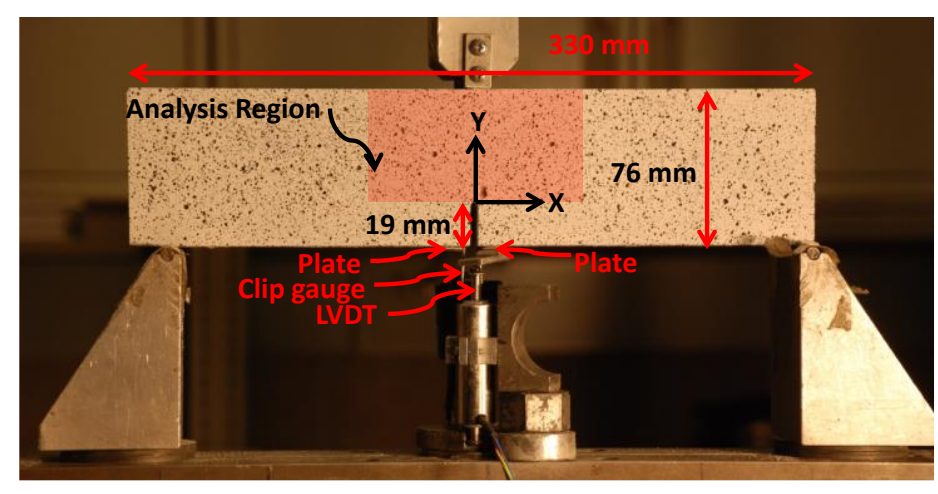

Figure 2: The three-point-bend experimental setup.

\subsection{Scanning Electron Microscopy}

The companion paste samples with different dosage of iron powder were subjected to a microstructural evaluation. Small rectangular pieces $(10 \times 10 \mathrm{~mm}$ in size $)$ were cut from the core of paste specimens using 
a diamond saw. Prior to polishing, the cut pieces were cleaned ultrasonically to remove the debris. Afterwards, the sample was impregnated in epoxy and vacuum-saturated followed by overnight curing. Several grinding/polishing steps were performed using SiC abrasives and finally the sample was polished using $0.04 \mu \mathrm{m}$ colloidal silica suspension. The polished samples were imaged using Philips XL30 field emission environmental scanning electron microscope (FESEM) under backscattered mode for microstructural evaluations.

\section{EXPERIMENTAL RESULTS AND DISCUSSIONS}

This section presents the experimental observation of the influence of iron powder on the strength and fracture response of mortars. Flexural response of prismatic beams are used in an inverse analysis procedure to obtain uniaxial tensile behavior of mortars. While the flexural response of the prismatic beams and the extracted tensile parameters serve as input to the multiscale numerical model for prediction of fracture response of particulate-reinforced mortars, the fracture response obtained from notched beams are used to validate the findings from the numerical simulations as explained later in this paper.

\subsection{Material Microstructure}

The companion paste samples were subjected to microstructural analysis after 28 days of hydration. Such an analysis provides a deeper insight into the distribution of iron particulates. Figure 3 shows representative micrographs for the mortar containing 30\% iron powder as cement-replacement. Distribution of bright (owing to higher density) elongated iron particulates are clearly visible in the backdrop of the gray phases indicating the reaction products and the black areas indicating pores in the BSE image. The elongated iron particles are likely to play a role in improving the fracture performance by crack bridging/deflection mechanisms as explored in the forthcoming section. Some matrix cracks can be observed which are a result of sample preparation. An image analysis of several BSE images yielded an average aspect ratio of 12 for the elongated iron particles which is used later in this paper in the generation of representative unit cells for the microstructural analysis. 


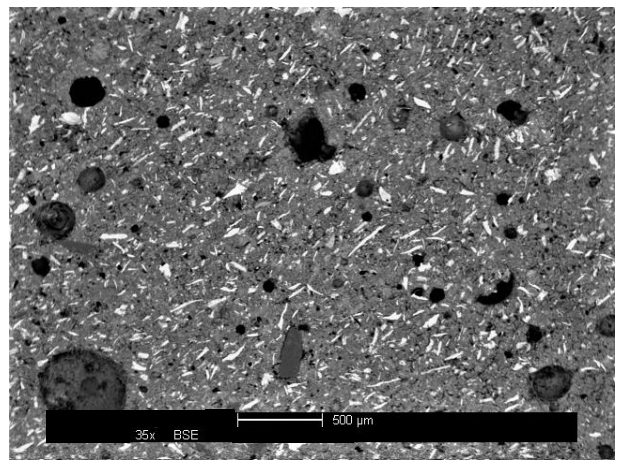

(a)

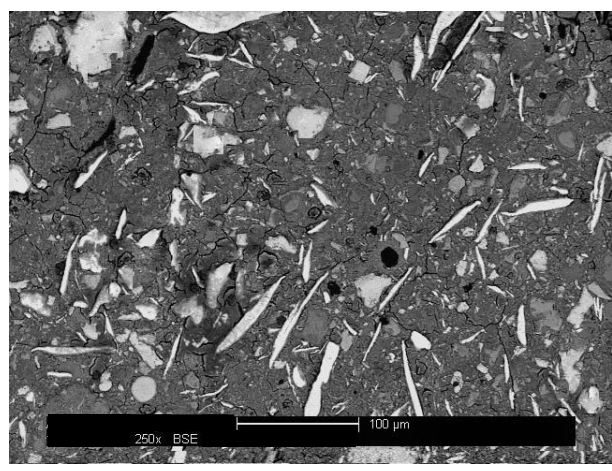

(b)

Figure 3: BSE image of iron particles (bright areas) dispersed in OPC paste matrix where 30\% volume of OPC is replaced by iron powder at (a) 35x (scale bar indicates $500 \mu \mathrm{m}$ and (b) 250x (scale bar indicates $100 \mu \mathrm{m})$

\subsection{Influence of particulate-reinforcement on compressive and flexural strength}

The compressive strengths of all the mixtures are found to be similar (38 $\pm 2.4 \mathrm{MPa})$ irrespective of volume fraction of iron powder. While the compressive strengths are similar for all the mixtures irrespective of iron powder content, a difference in flexural behavior is observed with increase in iron powder content. Figure 4(a) shows the load deflection behavior of the control and iron powder-incorporated mortars. With increasing iron powder content, the peak load and the slope of load-deflection curve increases indicating superior flexural performance and increase in Young's modulus due to incorporation of iron powder. The flexural strengths of the specimens are shown in Figure 4(b). It is observed that the flexural strength follows an increasing trend with increasing iron powder content. A gain in flexural strength of around $15 \%$ is obtained with incorporation of $30 \%$ iron powder. This can be explained from the fact that significant amount of stress is transferred from matrix to the stiffer iron particles resulting in stress-relaxation in the matrix and increase in the flexural strength of the mortars with incorporation of iron powder. The aspect of influence of iron particles on the microstructural stress-distributions is explained using finite element analysis (FEA) later in this paper for detailed insight. 

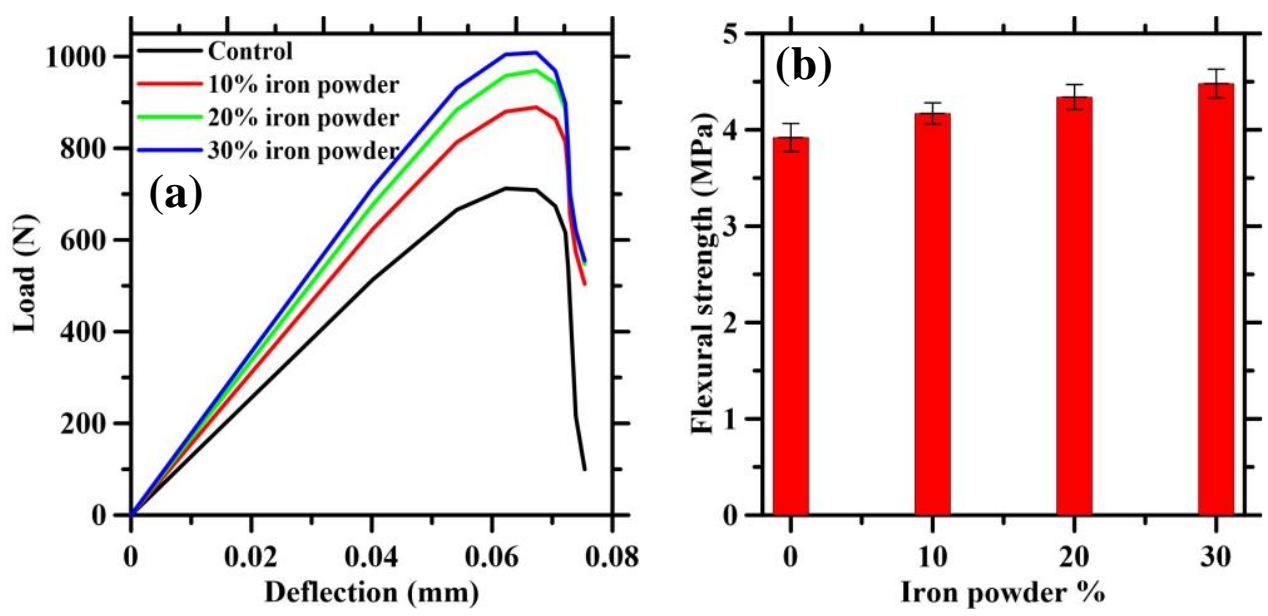

Figure 4: (a)Flexural load-deflection curves (b) Flexural strength for iron powder-incorporated mortars with varying iron powder content

\subsection{Influence of particulate-reinforcement on Flexural Fracture Response}

While the previous section explained the influence of iron powder on flexural strengths, this section explains the impact of particulate reinforcement on the fracture response of mortars after 28 days of hydration. The fracture response of the mortars are characterized using Hillerborg's work-of-fracture $[72,73]$ as well as two parameter fracture model (TPFM) [74].

\subsubsection{Load-CMOD responses}

The load-CMOD responses of control mortar and iron powder incorporated mortars are shown in Figure 5(a). The peak load increases with increase in the amount of iron powder included in the binder due to the reasons explained in the previous section. Additionally, the area under load-CMOD curve, which is a measure of the material toughness, increases significantly with increasing iron powder content signifying improved toughness of the material. Figure $5(\mathrm{~b})$ shows the size-dependent fracture energy $\left(\mathrm{G}_{1 \mathrm{C}}\right)$, calculated using Hillerborg's work-of-fracture method as shown in Equation 1.

$$
G_{1 C}=\frac{W_{0}+2 P_{w} \delta_{0}}{\left(D-a_{0}\right) t}
$$

Where $W_{0}$ is the area under load-CMOD curve for specimen of self-weight $P_{w}$ with depth $\mathrm{D}$, width $\mathrm{t}$ and notch height $a_{0}$ that can withstand a maximum CMOD $\delta_{0}$. Since similar specimens are used for each set of experiments, the otherwise size-dependent $G_{1 C}$ can be used for comparing the relative gain in performance with increasing volume fraction of iron powder. Figure 5(b) shows an increasing trend of work of fracture with increasing iron powder volume fraction indicating improved dissipation potential. About $42 \%$ increase in fracture energy is observed with incorporation of $30 \%$ iron powder as cement-replacement. These results 
serve as a motivation to study the fracture behavior of such systems in more depth, as elucidated in the following sub-sections.
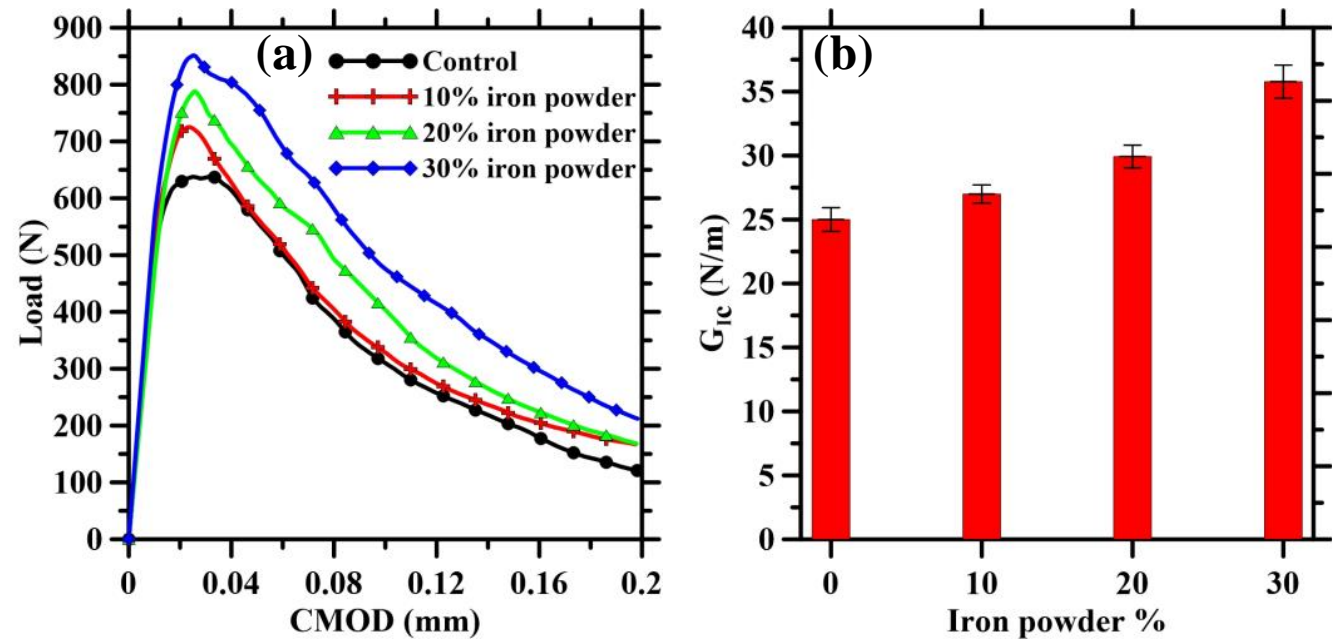

Figure 5: (a) Load-CMOD responses and (b) work of fracture for iron incorporated mortars with different iron powder contents

\subsubsection{Application of DIC towards fracture response}

This sub-section applies DIC to obtain TPFM parameters $\left(\mathrm{K}_{\mathrm{IC}}\right.$ and $\left.\mathrm{CTOD}_{\mathrm{C}}\right)$. As explained earlier, images obtained after the test are correlated to obtain displacement field using VIC-2D software [70]. Figure 6(a) shows a schematic representation of a 3D surface plot showing the horizontal displacement field. The crack tip opening displacement (CTOD) is computed from the displacement field as displacement-jump at the tip of the notch (see Figure 6(a)). Crack-extension $(\Delta \mathrm{a})$ is measured as the extent of the displacement-jump as shown in Figure 6(a). Displacement-jumps only above $0.005 \mathrm{~mm}$ were considered significant enough so as to contribute to crack extension in this study. Similar approach was successfully incorporated in $[14,42,45,50,75]$. The critical values of the fracture parameters $\mathrm{K}_{\mathrm{IC}}$ and CTODC correspond to a load of $95 \%$ of the peak load in the post-peak regime. At that point of loading, $\mathrm{CTOD}_{\mathrm{C}}$ is directly obtained from DIC and TPFM model yields the $\mathrm{K}_{\mathrm{IC}}$ using Equations $2 \mathrm{a}$ and $2 \mathrm{~b}$ [76].

$$
\begin{gathered}
K_{I C}=\frac{P L}{b d^{3 / 2}} F\left[\frac{a_{e f f}}{d}\right] \\
F\left[\frac{a_{e f f}}{d}\right]=\left[2.9\left(\frac{a_{e f f}}{d}\right)^{1 / 2}-4.6\left(\frac{a_{e f f}}{d}\right)^{3 / 2}+21.8\left(\frac{a_{e f f}}{d}\right)^{5 / 2}-37.6\left(\frac{a_{e f f}}{d}\right)^{7 / 2}+38.7\left(\frac{a_{e f f}}{d}\right)^{9 / 2}\right]
\end{gathered}
$$


Where the effective crack length $a_{\text {eff }}=a_{0}+\Delta a$ at the $95 \%$ of the peak load in the post-peak regime. Figure 6 (b) shows a representative digitally correlated image (for the control mortar) corresponding to 95\% of the peak load in the post-peak regime for obtaining the crack-extension ( $\Delta$ a) from horizontal $u$ displacement fields.

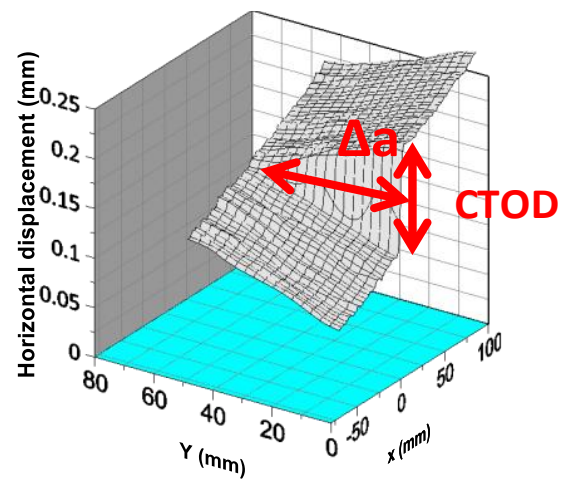

(a)

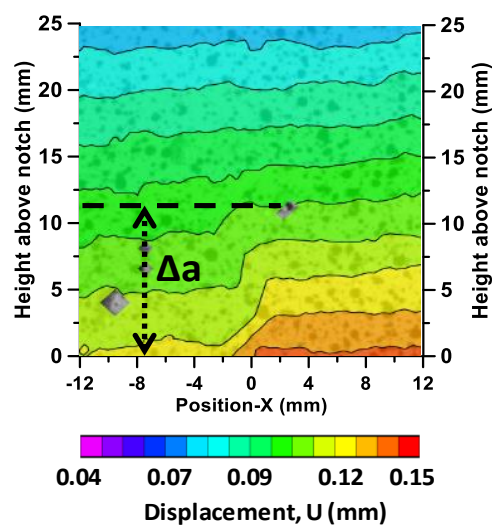

(b)

Figure 6 (a) schematic 3D surface plot showing correlation between displacement fields and fracture parameters and (b) the experimental result obtained to calculate crack growth

Figure 7 shows the two fracture parameters $\mathrm{K}_{\mathrm{IC}}$ and $\mathrm{CTOD}_{\mathrm{C}}$ for all the mixtures. About $36 \%$ increase in $\mathrm{K}_{\mathrm{IC}}$ is observed with incorporation of $30 \%$ iron powder. As can be observed in, The elongated iron particles (see Figure 3) serve as micro-reinforcements to facilitate crack bridging that improves the fracture response of such systems drastically. CTOD $_{C}$ signifies the threshold limit beyond which unstable crack propagation starts. $\mathrm{CTOD}_{\mathrm{C}}$ also increases significantly with increase in iron powder content thus indicating improved crack resistance of iron powder-modified mortars. 


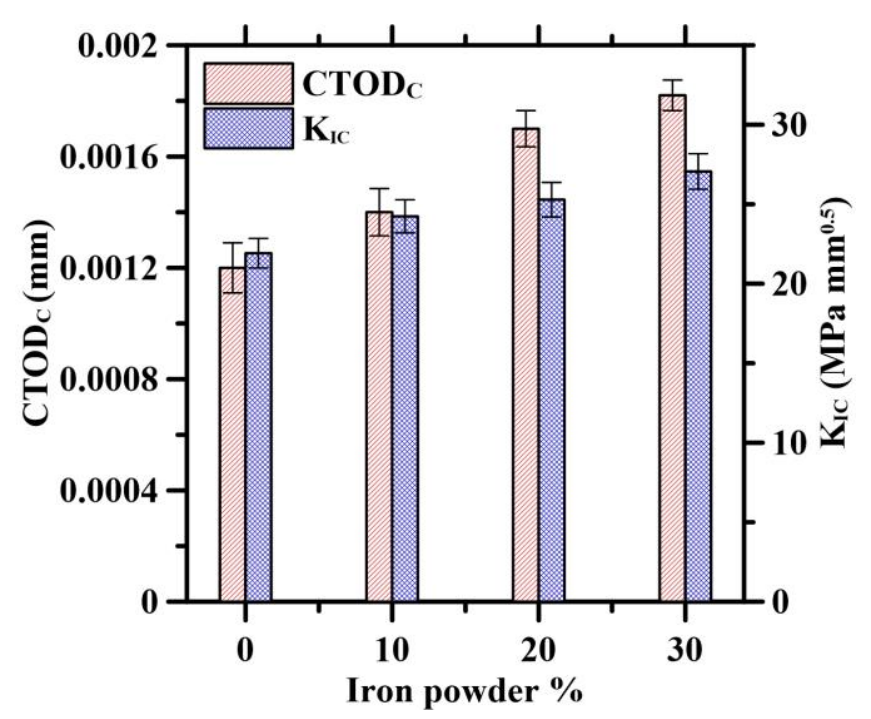

Figure 7: TPFM parameters fracture toughness $\left(\mathrm{K}_{\mathrm{IC}}\right)$ and critical crack tip opening displacement $\left(\mathrm{CTOD}_{\mathrm{C}}\right)$ for mortars with different iron powder replacing cement by volume

\section{$\underline{\text { 3.3.4 Extraction of tensile parameters of composite mortars }}$}

While the previous sub-section elucidated the influence of iron powder inclusion on the fracture response of mortars, this section uses the load-deflection behavior obtained from prismatic beam sections (shown in Figure 4(a)) towards a moment-curvature-based inverse analysis approach [71] to extract uniaxial tensile parameters (tensile strength $\mathrm{f}_{\mathrm{t}}$, the modulus of elasticity $\mathrm{E}$, the peak strain $\varepsilon_{D_{0}}$ and the strain near failure $\left.\varepsilon_{t u}\right)$ for the mortars, which are otherwise difficult to obtain experimentally. The inverse analysis approach has been successfully incorporated in [45] and is adequately detailed in [77]. Table 2 quantifies the tensile parameters as a function of iron powder content for the mortars. An increasing trend of tensile strength for mortars is observed with increasing volume fraction of iron powder which is in line with the flexural strength observations. The Young's modulus (E) increases with increase in iron powder content since iron powder has a higher $\mathrm{E}$ than the cement it replaces. The $\mathrm{f}_{\mathrm{t}}$ and $\varepsilon_{t u}$ also increases with increasing iron powder content signifying the higher toughness of the particulate reinforced composites. The values of $\varepsilon_{D_{0}}$ are fairly consistent for all the specimens. The tensile parameters, thus obtained, serve as input to multiscale numerical models for prediction of fracture response as explained in the forthcoming section. 
Table 2. Extracted tensile parameters of mortar as a function of iron powder content

\begin{tabular}{|c|c|c|c|c|}
\hline $\begin{array}{c}\text { Iron } \\
\text { powder } \\
\boldsymbol{\%}\end{array}$ & $\begin{array}{c}\mathbf{f}_{\mathbf{t}} \\
(\mathbf{M P a})\end{array}$ & $\boldsymbol{\varepsilon}_{\boldsymbol{D}_{\mathbf{0}}}$ & $\mathbf{E}(\mathbf{G P a})$ & $\boldsymbol{\varepsilon}_{\boldsymbol{t} \boldsymbol{u}}$ \\
\hline 0 & 3.12 & 0.00013 & 23.9 & 0.000295 \\
\hline 10 & 3.79 & 0.00013 & 29.1 & 0.000305 \\
\hline 20 & 4.26 & 0.00014 & 34.1 & 0.000310 \\
\hline 30 & 4.73 & 0.00014 & 39.8 & 0.000315 \\
\hline
\end{tabular}

\section{MULTISCALE NUMERICAL SIMULATION}

While the previous section elucidated experimental evaluation of flexural strength and fracture behavior of particulate-reinforced mortars, this section is aimed towards simulation of fracture behavior of such systems. In order to encompass the complex heterogeneity of cementitious systems that contains random microstructure at different length scales, the numerical simulation framework, presented here, performs numerical homogenization at different length scales involving continuum micromechanics so as to obtain homogenized constitutive behavior of the material that serves as input to macro-scale model. Such an approach involves representation of the geometrical configuration of the different phases in the form of representative volume element (RVE) at different length scales. In this study, two interactive length scales at the paste level and mortar level are used to predict the fracture behavior of the iron powder-modified mortars which is validated with the experimental observations presented earlier in this paper. The forthcoming sub-sections explain the numerical simulation approach and apply the framework towards prediction of fracture response of particulate-reinforced mortars.

\subsection{Multiscale Numerical Simulation Approach for prediction of effective constitutive response and} Fracture behavior

The framework aims to elucidate the influence of addition of particulate inclusions on the macroscale fracture response of inclusion modified heterogenous system. The numerical framework implements cohesive zone model (CZM)-based debonding using continuum damage approach $[80,81]$ at the matrixinclusion interfaces and an isotropic damage model in the matrix $[62,63,80]$ of the RVEs towards achieving the effective constitutive response in the post-peak regime. The effective tensile constitutive response, thus predicted, is used to simulate three-point-bend test of notched beams to obtain TPFM parameters.

\subsubsection{Prediction of Effective Constitutive Response}

Prediction of effective constitutive response involves generation of RVE based on known microstructural features of the material, application of appropriate boundary conditions on the RVE, meshing the RVE and 
application of uniaxial strain to obtain stress-response. The current study incorporates debonding at the matrix-inclusion interfaces by incorporating cohesive zero thickness interface elements and interfacial debonding is implemented using a continuum approach coupled with CZM [80]. Similar approach was successfully implemented to evaluate electro-mechanical response of self-sensing structural materials in [81].The current approach also implements isotropic damage in the matrix so as to obtain the post-peak effective constitutive response of the composite. Figure 8 shows a schematic representation of the numerical homogenization approach and the forthcoming sub-sections elucidate different components of the approach.

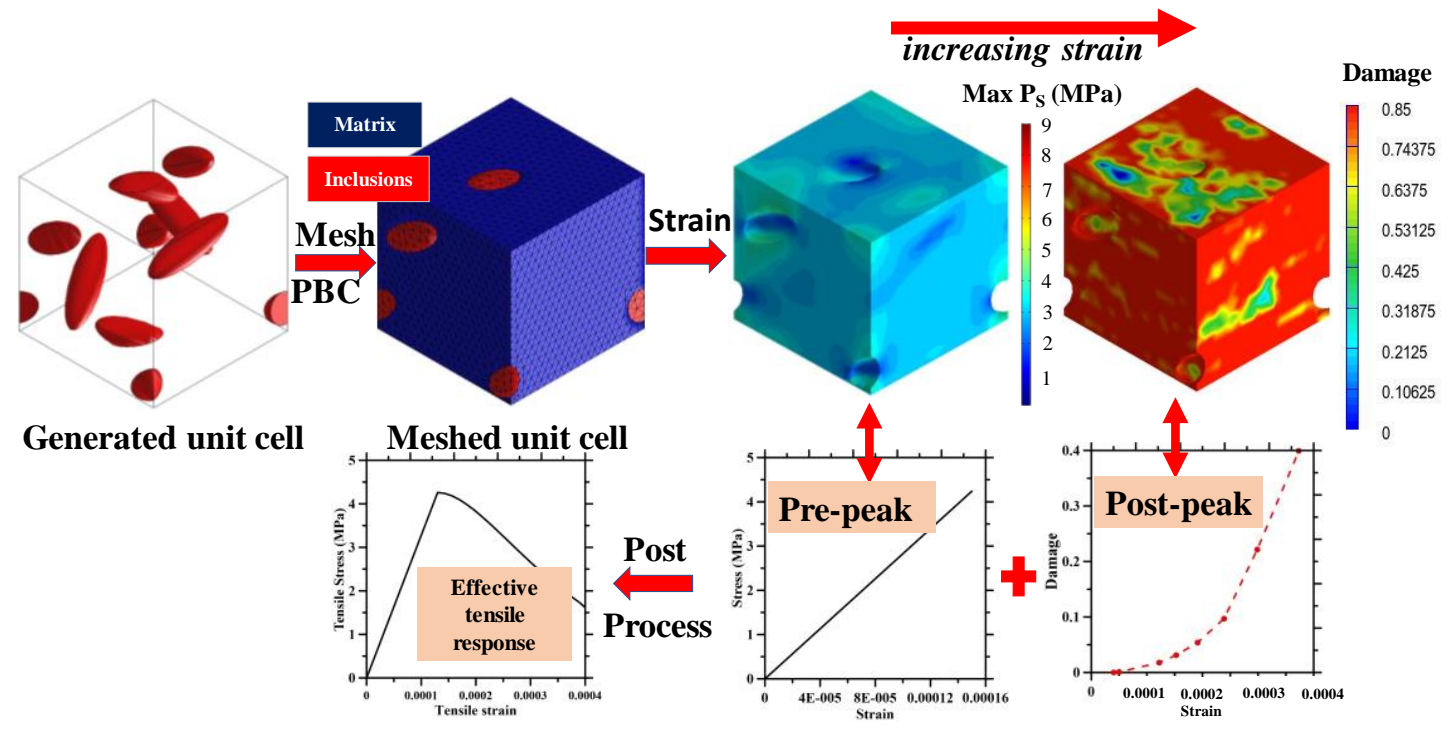

Figure 8: schematic representation of the numerical homogenization approach

\subsubsection{Generation of unit cell: general schematic}

The unit cells are generated here using the Lubachhevsky-Stillinger algorithm [82,83]. This algorithm employs a hard contact model and hence particle overlaps are not allowed. Finally, the obtained microstructural information is implemented via a python language script to enable it to be imported to a commercial finite element software. The unit cell generation algorithm has been successfully implemented in [55] and adequately detailed in [81].

\subsubsection{Boundary conditions}

Once the unit cell is generated, it is meshed using the python script and periodic boundary conditions (PBC) $[81,84]$ are applied. PBCs ensure a continuity of displacement and traction across boundaries of neighboring unit cells. PBCs have been applied successfully towards FE analysis of random heterogenous materials [85]. PBCs are shown to be computationally efficient even with smaller size of unit cells facilitating faster 
convergence[55]. More details on the PBC can be found in $[51,86]$. The meshed RVE with PBC is subjected to uniaxial tensile strain to simulate a displacement-controlled test scenario. In order to incorporate interfacial debonding and the damage-in the matrix, the numerical homogenization approach implements CZM-based damage at the interface and isotropic damage in the matrix as detailed in the forthcoming subsections.

\subsubsection{CZM damage for interfacial debonding}

Interfacial debonding is implemented here using CZM coupled with continuum damage. Here, a continuity in displacement is ensured by implementation of zero-thickness interface elements. Such zero-thickness interface elements have been implemented successfully to model relative slip or separation on a predetermined surface in [80,81]. The CZM implements Mode I fracture when the stress state reaches the tensile strength of the matrix. Traction separation law which governs the propagation of damage is characterized here using an equivalent interface opening, $\lambda$ (Equation 3(a)) and equivalent traction, $\sigma_{\mathrm{c}}$ (defined in Equation 3(b)) [60,80,81].

$$
\begin{gathered}
\lambda=\sqrt{\left\langle\llbracket u_{n} \rrbracket\right\rangle^{2}+\llbracket u_{t} \rrbracket^{2}} \\
\sigma_{\mathrm{c}}=\left\{\begin{array}{c}
\mathrm{K}_{\mathrm{p}} \lambda, \lambda<\lambda_{0} \\
f_{t} \exp \frac{-f_{t}\left(\lambda-\lambda_{0}\right)}{G_{F}}, \lambda \geq \lambda_{0}
\end{array}\right.
\end{gathered}
$$

Where $u_{n}$ and $u_{t}$ are normal and tangential displacement jumps, $\lambda_{0}$ is the threshold limit [80,81] defined

by $\frac{2 G_{f}}{f_{t}}\left(\mathrm{G}_{f}\right.$ is initial fracture energy) up to which the $\sigma_{\mathrm{c}}$ increases with $\lambda$ with a linear coefficient $\mathrm{K}_{\mathrm{p}}$ (penalty stiffness), $f_{t}$ is tensile strength, $G_{F}$ is total fracture energy. Equivalent normal traction $t_{c n}$ and tangential traction $t_{c t}$ are obtained by partially differentiating the volume integral of $\sigma_{c}$ with respect to $u_{n}$ and $u_{t}$ respectively. The mechanical tangent material matrix $\mathrm{C}_{c}^{u}$ can be expressed as partial derivatives of the resulting traction with respect to displacement jump as shown in Equation 4 [80,81].

$$
\mathrm{C}_{c}^{u}=\left[\begin{array}{ll}
\frac{\partial t_{c n}}{\partial \llbracket u_{n} \rrbracket} & \frac{\partial t_{c n}}{\partial \llbracket u_{t} \rrbracket} \\
\frac{\partial t_{c t}}{\partial \llbracket u_{n} \rrbracket} & \frac{\partial t_{c t}}{\partial \llbracket u_{t} \rrbracket}
\end{array}\right]
$$

The tangent material matrix $\mathrm{C}_{c}^{u}$ is transformed to the local co-ordinate system to obtain mechanical stiffness matrix of each cohesive element. While the penalty stiffness governs the traction-separation law with increase in $\lambda$ when $\lambda<\lambda_{0}$, the mechanical stiffness matrix is modified at every iteration with increasing $\lambda$ based on phenomenological damage model when $\lambda \geq \lambda_{0}$ [80]. Here, progressive debonding has been characterized with increasing $\lambda$ using a scalar interface damage parameter $D_{c}$ which is defined as follows [81]: 


$$
D_{c}=\frac{\lambda}{\lambda_{c r}}
$$

Where $\lambda_{c r}$ corresponds to equivalent interface opening at very low traction values in the post-peak regime of the traction-separation behavior, generally computed at $0.1 f_{t}$ in the post-peak regime. The numerical simulation is implemented using user defined subroutine in $\mathrm{ABAQUS}^{\mathrm{TM}}$ and it requires initial fracture energy $\left(\mathrm{G}_{f}\right)$, total fracture energy $\left(G_{\mathrm{F}}\right)$ and tensile strength of matrix $\left(f_{t}\right)$ as input $[81,87]$.

\subsubsection{Isotropic damage in matrix}

Isotropic damage is implemented in the simulation framework to quantify the stiffness loss for a strain state beyond cracking strain $\left(\varepsilon_{D_{0}}\right)$. Assuming isotropic stiffness degradation, the damage variable, $D$ is given as [62-64,81]:

$$
\sigma=(1-D) C: \varepsilon
$$

Where the effective stress tensor is denoted by $\sigma, \mathrm{C}$ denotes fourth order tensor of elasticity and $\varepsilon$ is the strain tensor. The value of damage, D ranges from 0 (undamaged) to 1 (completely damaged). The damage rate denoted by $\dot{D}$ assumes only zero or positive values [82]. A non-local equivalent strain $\tilde{\varepsilon}$ is used to obtain the damage, $D$ which is defined as [64].

$$
\tilde{\varepsilon}=\sqrt{\sum_{i}<\varepsilon_{i}>_{+}^{2}}
$$

Where $\left\langle\varepsilon_{i}\right\rangle_{+}$is the positive part of the principal strain. The damage $D$ evolve as a function of $\tilde{\varepsilon}$ as per the Equation 8 for uniaxial tensile strains:

$$
D(\tilde{\varepsilon})=1-\frac{\varepsilon_{D_{0}}\left(1-A_{t}\right)}{\tilde{\varepsilon}}-\frac{A_{t}}{\exp \left[B_{t}\left(\tilde{\varepsilon}-\varepsilon_{D_{0}}\right)\right]}
$$

Where $\varepsilon_{D_{0}}$ is damage initiation threshold defined as

$$
\varepsilon_{D_{0}}=\frac{f_{t}}{E}
$$

Thus, the isotropic damage model requires the tensile strength $\left(f_{t}\right)$ of the matrix and the damage propagation parameters $A_{t}$ and $B_{t}$ (see Equation 8) to fully characterize the post peak tensile constitutive response at strains exceeding $\varepsilon_{D_{0}}$. The isotropic damage is implemented here using user defined subroutine in ABAQUS ${ }^{\mathrm{TM}}$. The tensile constitutive response and the isotropic scalar damage variable $\mathrm{D}$ can be used to obtain fracture energy $G_{F}$. Isotropic damage has been used successfully $[57,88]$ to correlate $f_{t}$ and fracture 
energy $\mathrm{G}_{\mathrm{F}}$ for stiffer inclusions embedded in a softer matrix and the relationship is defined as shown in Equation 10 [57].

$$
(1-D) \varepsilon=\varepsilon_{D_{0}} \exp \left(-\frac{D h \varepsilon f_{t}}{G_{F}}\right)
$$

Where $\mathrm{D}$ is damage variable expressed in Equation $8, \varepsilon$ is the strain response of the tensile constitutive relation with its value being $\varepsilon_{0}$ corresponding to the tensile strength $f_{t}$; h is a mesh dependent parameter defining the mean distance between centroids of adjoining elements and $G_{F}$ is fracture energy. In multiscale simulations of particulate-reinforced mortars, $\mathrm{G}_{\mathrm{F}}$ obtained for microscale (inclusion modified hardened cement paste), is used as input to the CZM-damage debonding model at the matrix -inclusion interfaces in the mesoscale (mortar). Thus, the procedure explained herein, can be invoked for translating mesoscale damage to macroscale fracture energy analysis.

\subsubsection{Post-processing and Effective Constitutive Response}

The analysis is implemented using ABAQUS ${ }^{\mathrm{TM}}$ solver to obtain stress distributions, debonding status as well as isotropic damage parameter D in the RVE. A post-processing module coded in MATLAB ${ }^{\circ}$ implements a volume computation thereby yielding a volume averaged stress-strain relation thus providing the effective constitutive tensile response.

\subsubsection{Upscaling to macro-scale Fracture Response}

The effective constitutive tensile response as well as the fracture energy, mentioned in the previous subsection, is obtained at different length scales to finally provide input to a macro-scale analysis of threepoint-bend test on notched beams. The macro-scale simulation is performed using extended finite element method (XFEM) which incorporates a maximum principal stress-based damage initiation criteria and a bilinear traction-separation law coupled with a damage plasticity model for propagation of damage.

The XFEM-based damage model initiates damage if the maximum principal stress exceeds the tensile strength. A bilinear traction-separation law [87] coupled with concrete damage plasticity model [66] is used for damage propagation. In this model, isotropic damage is represented as:

$$
\sigma=(1-d) D_{0}^{e l}:\left(\varepsilon-\varepsilon^{p l}\right)=D^{e l}:\left(\varepsilon-\varepsilon^{p l}\right)
$$

where $\sigma$ is the Cauchy stress tensor, $\mathrm{d}$ is the scalar stiffness degradation variable, $\varepsilon$ is the strain tensor,

$\varepsilon^{\mathrm{pl}}$ is the plastic strain, $D_{0}^{e l}$ is the initial elastic stiffness of the material, and $D^{e l}$ is the degraded elastic stiffness tensor. The effective stress tensor $\bar{\sigma}$ is given as: 


$$
\bar{\sigma}=D_{0}^{e l}:\left(\varepsilon-\varepsilon^{p l}\right)
$$

The plastic flow is given as [66]:

$$
\dot{\varepsilon}^{p l}=\dot{\lambda} \frac{\partial G(\bar{\sigma})}{d \bar{\sigma}}
$$

where, the flow potential, $G$ is given using a Drucker-Prager hyperbolic function as:

$$
G=\sqrt{\left(f_{c}-m \cdot f_{t} \cdot \tan \beta\right)^{2}+\bar{q}^{2}}-\bar{p} \cdot \tan \beta-\sigma
$$

Here, $f_{t}$ is the tensile strength and $f_{c}$ is the compressive strength, $\beta$ is the dilation angle and $\mathrm{m}$ is the eccentricity of the plastic potential surface, $\bar{p}$ is the effective hydrostatic stress and $\bar{q}$ is the Mises equivalent effective stress. The CDP model uses a yield condition based on loading function:

$$
F=\frac{1}{1-\alpha}\left(\bar{q}-3 \cdot \alpha \cdot \bar{p}+\theta\left(\varepsilon^{p l}\right)\left\langle\bar{\sigma}_{\max }\right\rangle-\gamma\left\langle-\bar{\sigma}_{\max }\right\rangle\right)-\bar{\sigma}_{c}\left(\varepsilon^{p l}\right)
$$

where the function $\theta\left(\varepsilon^{p l}\right)$ is given as:

$$
\theta\left(\varepsilon^{p l}\right)=\frac{\bar{\sigma}_{c}\left(\varepsilon_{c}^{p l}\right)}{\bar{\sigma}_{t}\left(\varepsilon_{t}^{p l}\right)}(1-\alpha)-(1+\alpha)
$$

The parameter $\alpha$, a function of biaxial compressive strength $\left(f_{b 0}\right)$ and uniaxial compressive strength $\left(f_{c}\right)$, is defined as follows:

$$
\alpha=\frac{\left(f_{b 0} / f_{c}\right)-1}{2\left(f_{b 0} / f_{c}\right)-1}
$$

The CDP model $[66,67]$ requires input parameters $\beta, m, \gamma$ (determines the shape of the loading surface in deviatoric plane) and $\alpha$. To calculate fracture toughness $\mathrm{K}_{\mathrm{IC}}$, the crack-extension values, obtained from simulations at $95 \%$ peak load in the post-peak regime are used. Using the simulated crack-extension values $\mathrm{K}_{\mathrm{IC}}$ can be calculated using Equations 2(a) and 2(b) as explained earlier in this paper. While $\mathrm{K}_{\mathrm{IC}}$ can be obtained from Equation 2, $\mathrm{CTOD}_{\mathrm{C}}$ can be computed directly from the XFEM simulations as the horizontal displacement at the tip of the notch. Thus, the numerical simulation approach, presented here, links different interactive length-scales and obtains macro-scale fracture response facilitating microstructure-guided material design towards improved toughness. The forthcoming section elucidates application of the multiscale numerical simulation approach towards prediction of macro-scale fracture parameters of iron powder-modified mortars. 


\subsection{Multiscale Numerical Simulation of fracture response in particulate-reinforced mortars}

The numerical simulation of fracture response in particulate-reinforced mortars involves three interactive length scales at the cement paste scale, mortar scale and macro-scale (simulation of three-point-bend test) as shown in Figure 9 for a representative mixture containing 10\% iron powder. The constitutive response and fracture energy obtained for particulate-reinforced hardened cement paste (Figure 9(a)) are assigned as the matrix property in the mesoscale containing the homogenized matrix and sand particles (Figure 9(b)). The constitutive response and fracture energy extracted from mesoscale are used towards XFEM simulation (Figure 9(c)) of three-point-bend test of notched beams to obtain $\mathrm{K}_{\mathrm{IC}}$ and CTODC. Although the numerical simulation is performed for the control mixture as well as all the mixtures with different dosage of iron powder, the generated micrographs and matrix/interface damage are shown for a representative simulation of the mixture containing $10 \%$ iron powder. The results are plotted for all the mixtures for a comparative evaluation.

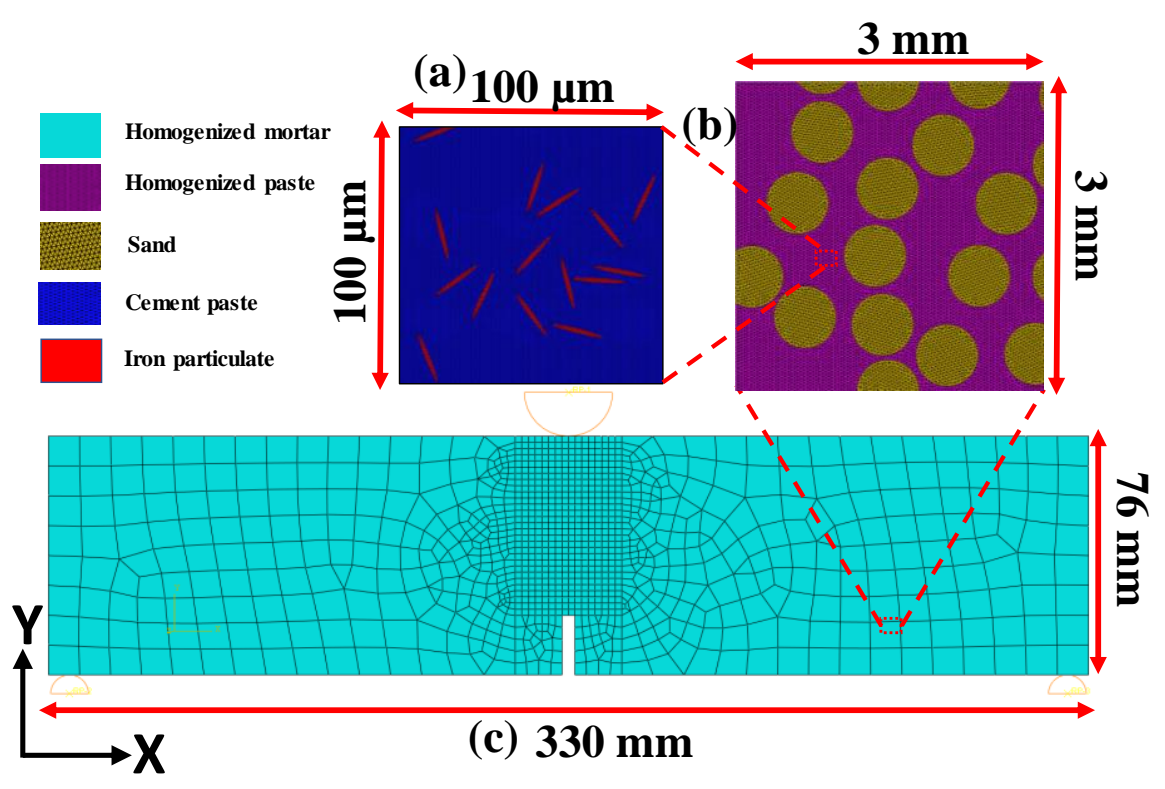

Figure 9. Interactive length scales representing the (a) micro-scale HCP with $10 \%$ iron powder; (b) mesoscale mortar with sand embedded in modified HCP (c) macro-scale mortar TPB notched beam

Implementation of interface damage and isotropic damage in the matrix requires inputs such as fracture energy and isotropic damage model parameters, as explained earlier in this paper. While the these parameters for hardened cement paste are available in the literature [89], the parameters for inclusionmodified matrices are not readily available. The numerical simulation approach, presented in this paper, 
uses the macro-scale tensile parameters of inclusion-modified mortars, extracted from the flexural response of the prismatic beams, as input to the multiscale numerical model to determine the parameters for isotropic damage model for iron-powder modified HCP (see Figure 9(a)). In this paper, the properties of the interface elements are assumed to be similar to those of the matrix owing to lack of data. Similar methodology was successfully adopted in [81,90]. Although the numerical simulation approach presented in this paper can incorporate 3D unit cells, here 2D unit cells are incorporated as a trade-off between computational efficiency and demand. 2D unit cells have been successfully implemented to evaluate damage in quasibrittle materials in [81,91]. In order to determine the representative size of unit cells, a sensitivity study was performed and the representative size of the unit cells at different length scales are shown in Figure 9. Sizes of unit cells beyond these adopted edge lengths resulted in insignificant change in the constitutive response. Median size of inclusions, reported in Section 2.1, are adopted for numerical simulation. As can be observed from the microstructure in Figure 3, the shape of the iron particulates in the powder are mostly elongated. Microstructural image analysis on several BSE micrographs yields an average aspect ratio of 12 which is used as a reference for generating iron particulate inclusions in the micro-scale. The following sub-sections elucidate the parameter identification for interface damage/isotropic damage model for the iron powder incorporated $\mathrm{HCP}$, perform numerical homogenization at two different length scales and implement macroscale XFEM analysis of three-point-bend test to obtain TPFM parameters of the particulate-reinforced mortars.

\subsubsection{Material Properties for Numerical simulation and Parameter identification for interface damage/isotropic damage model}

Damage model parameters $\left(\boldsymbol{f}_{\boldsymbol{t}}, \boldsymbol{\varepsilon}_{\boldsymbol{D}_{\mathbf{0}}}, \mathbf{A}_{\mathbf{t}}, \mathbf{B}_{\mathbf{t}}\right.$ and $\left.\mathbf{G}_{\mathbf{F}}\right)$ for iron powder-modified HCP are tuned in a way so that the simulated tensile constitutive response for particulate-reinforced mortars matches with the experimental tensile constitutive response, obtained through inverse analysis from flexural response of prismatic beam sections as explained in the Section 3.3.4. The identified parameters for all the mixtures are reported in Table 3. The parameters identified for the control HCP correlates well with the values reported in $[64,89]$, thus validating the parameter identification approach presented here. The Young's modulus for $\mathrm{HCP}$, sand and iron particulates are considered $20 \mathrm{GPa}, 70 \mathrm{GPa}$ and $200 \mathrm{GPa}$ [55,81]. A constant Poisson's ratio of 0.2 is used for all the simulations presented in this paper since variation of Poisson's ratio in the range of 0.17-0.22 has been shown to result in insignificant changes in the results [85,92]. $\mathrm{G}_{\mathrm{f}}$ is assumed to be 0.6 times that of $G_{F}$. Similar value of $G_{f}$ with respect to $G_{F}$ has been successfully implemented for quasi brittle materials in [93]. 
Table 3: Material properties and parameters for iron powder modified HCP

\begin{tabular}{|c|c|c|c|c|c|c|}
\hline & $\begin{array}{c}\text { Iron } \\
\text { Powder \% }\end{array}$ & $\begin{array}{c}\boldsymbol{f}_{\boldsymbol{t}} \\
(\mathbf{M P a})\end{array}$ & $\boldsymbol{\varepsilon}_{\boldsymbol{D}_{\mathbf{0}}}$ & $\mathbf{A}_{\mathbf{t}}$ & $\mathbf{B}_{\mathbf{t}}\left(\mathbf{1 0}^{\mathbf{4}}\right)$ & $\begin{array}{c}\mathbf{G}_{\mathbf{F}} \\
(\mathbf{N} / \mathbf{m m})\end{array}$ \\
\hline \multirow{2}{*}{$\begin{array}{c}\text { Micro-scale } \\
\text { (HCP-iron } \\
\text { powder } \\
\text { composite) }\end{array}$} & 0 & 1.78 & 0.000100 & 0.98 & 1.15 & 0.017 \\
\cline { 2 - 7 } & 10 & 2.16 & 0.000105 & 0.99 & 1.18 & 0.019 \\
\cline { 2 - 7 } & 20 & 2.43 & 0.000110 & 1.00 & 1.21 & 0.022 \\
\hline
\end{tabular}

\section{$\underline{\text { 4.2.2 Multi-scale effective constitutive response }}$}

This section reports the multiscale numerical homogenization results. First, numerical homogenization is performed in micro-scale (refer to Figure 9(a)). The meshed unit cell, shown in Figure 9(a) is subjected to periodic boundary conditions and a uniaxial tensile strain along $\mathrm{X}$ direction as explained earlier in this paper. The fracture energy and the isotropic damage parameters, reported for control HCP in Table 3 are adopted since the matrix remains same (HCP with same mass-based water-to-cement ratio of 0.5) irrespective of the dosage of iron powder. The analysis is performed using ABAQUS ${ }^{\mathrm{TM}}$ solver and the simulation yields progressive interface damage and damage in the matrix as shown in Figure 10.

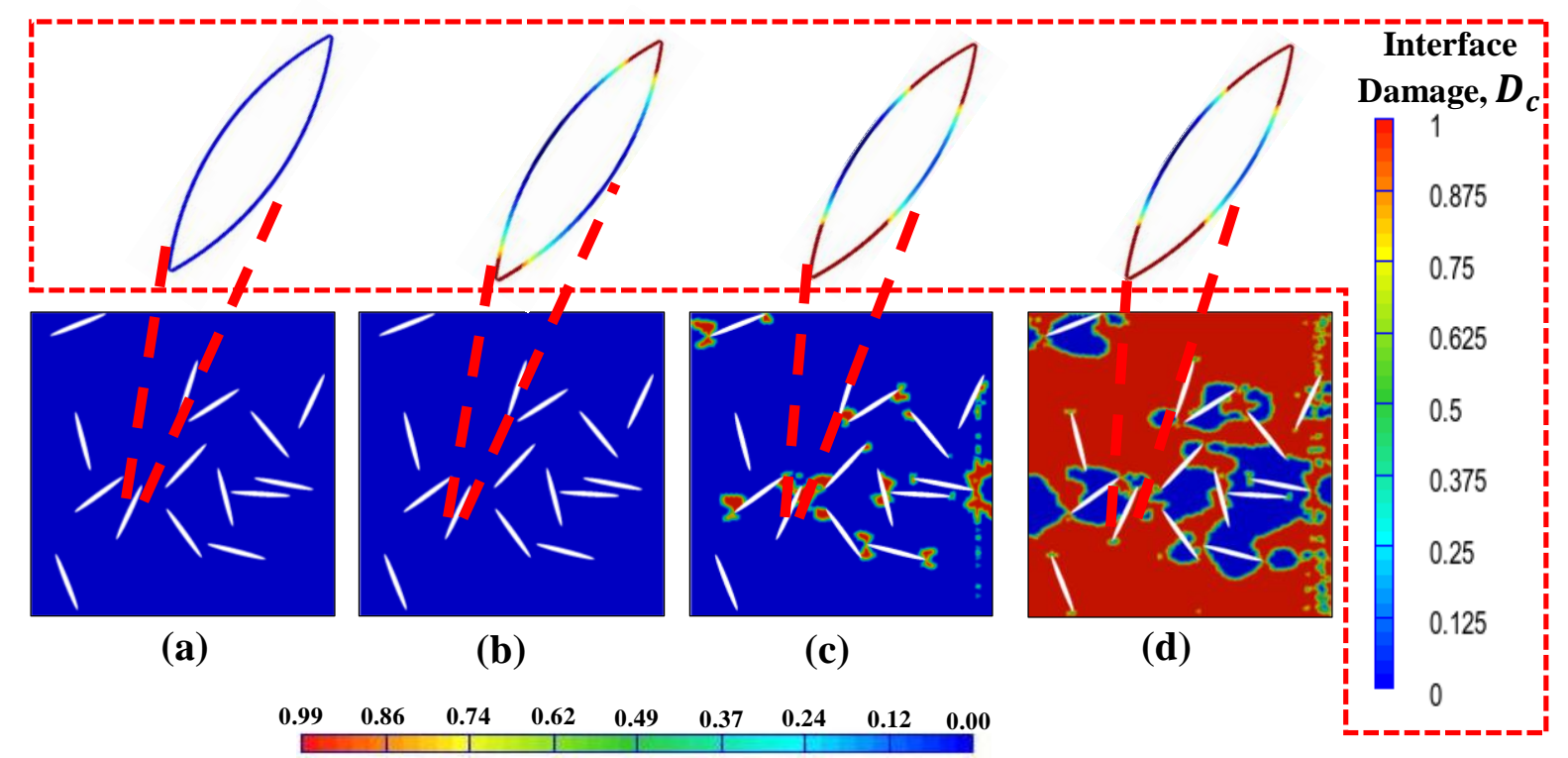

\section{Damage, D}

Figure 10. Progressive interface damage and damage in iron particulate-reinforced HCP containing $10 \%$ iron powder for applied strain of (a) $0 \%$ (undeformed), (b) $0.004 \%$, (c) $0.0106 \%$ and (d) $0.012 \%$.

While Figure 10(a) correspond to undeformed configuration (no applied strain), Figures 10(b), (c) and (d) correspond to applied uniaxial strain of $0.004 \%, 0.0106 \%$ and $0.012 \%$ respectively. Interfacial debonding 
sets in at a strain lower than the peak strain and it keeps on propagating resulting in progressive increase in stress in the matrix. The debonding stops propagating once the matrix stresses reach the tensile strength, beyond which progressive damage in the matrix begins initiating the post-peak response. These are clearly reflected in Figure 10. Figure 11 shows the generated tensile constitutive response of iron particulatereinforced HCP with different dosage of iron powder. Incorporation of iron powder leads to a higher tensile strength that corroborates the gain in fracture toughness.

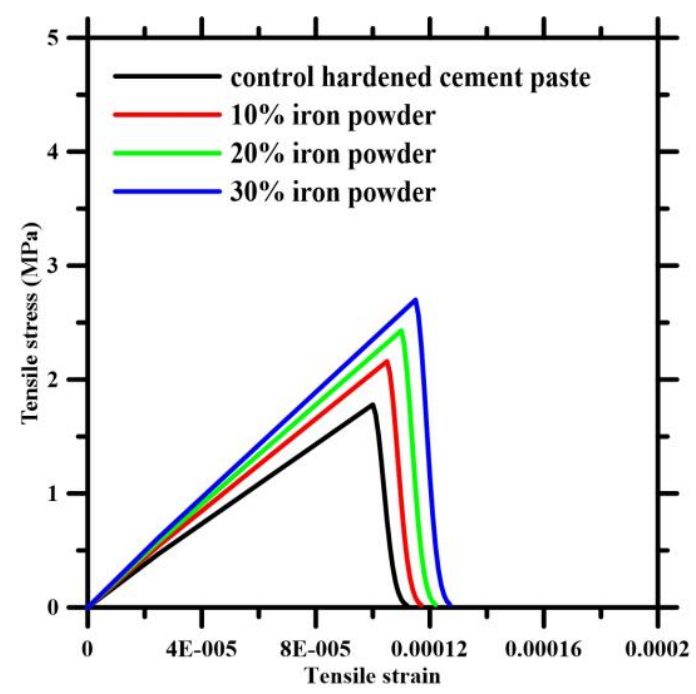

Figure 11: Simulated tensile constitutive response of control HCP as well as iron powder-modified HCP containing various dosage of iron powder

The homogenized tensile constitutive response for particulate-reinforced HCP along with the damage model parameters and $\mathbf{G}_{\mathbf{F}}$ are assigned to the matrix in the mortar scale (see Figure 9(b)). Figure 12 presents the progressive interface damage and damage in iron particulate-reinforced mortar containing $10 \%$ iron powder. While Figure 12(a) corresponds to undeformed configuration for the meso-scale showing undeformed matrix and sand inclusions, Figures 12(b), (c) and (d) present the interface damage parameter as well as the matrix damage variable (D) under applied strain of $0.005 \%, 0.017 \%$ and $0.03 \%$ respectively. General trend in progressive interface debonding and damage in the matrix remains similar to that observed in the micro-scale. Figure 13 shows the computed tensile constitutive response for control mortar as well as iron powder-modified mortars. $\mathbf{G}_{\mathbf{F}}$ for the mortars are obtained from simulated tensile softening responses using Equation 10 and the values are found to be $0.034,0.038,0.043$ and $0.048 \mathrm{~N} / \mathrm{mm}$ for control mortar and mortars containing $10 \%, 20 \%$ and $30 \%$ iron powder respectively. $\mathrm{G}_{\mathrm{f}}$ values are adopted as 0.6 times that of $\mathrm{G}_{\mathrm{F}}[93]$ as explained earlier. The simulated tensile constitutive responses and fracture energies, thus obtained using numerical homogenization, serve as input to simulate macro-scale three-point-bend tests as explained in the forthcoming section. 


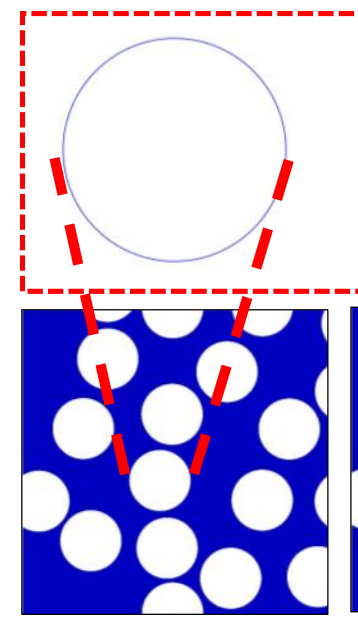

(a)

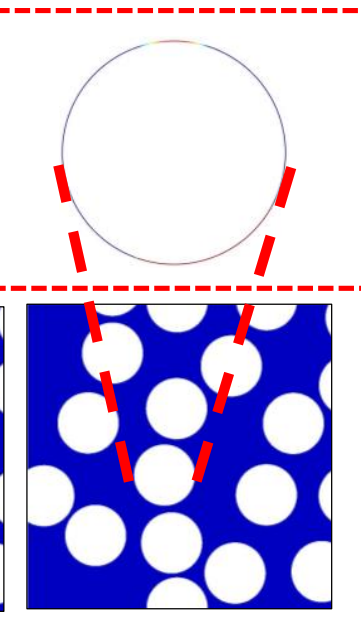

(b)

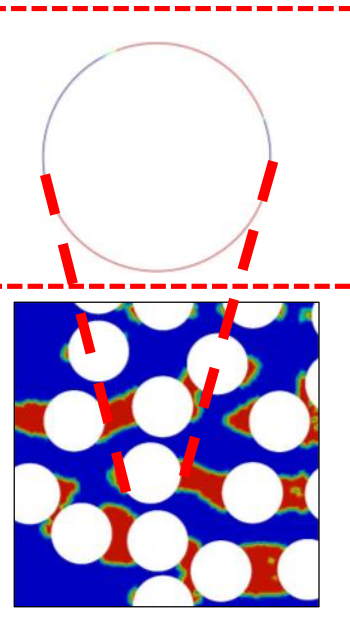

(c)

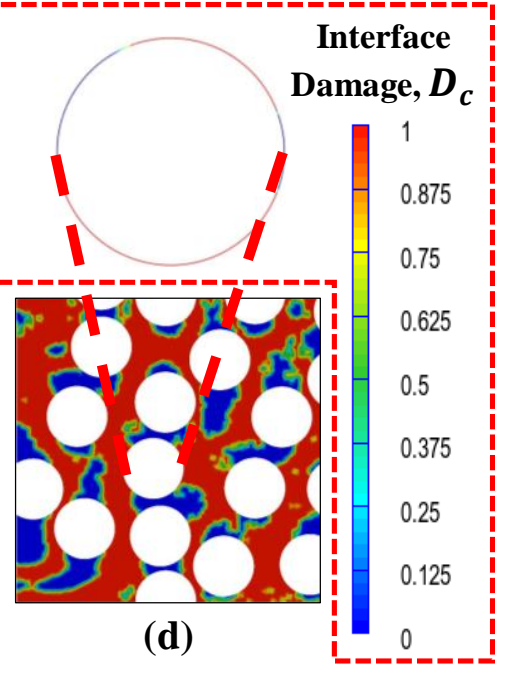

$\begin{array}{lllllllll}0.99 & 0.86 & 0.74 & 0.62 & 0.49 & 0.37 & 0.24 & 0.12 & 0.00\end{array}$

Damage, D

Figure 12. Progressive interface damage and damage in iron particulate-reinforced mortar containing $10 \%$ iron powder for applied strain of: (a) $0 \%$ (undeformed), (b) $0.005 \%$, (c) $0.017 \%$, and (d) $0.03 \%$.

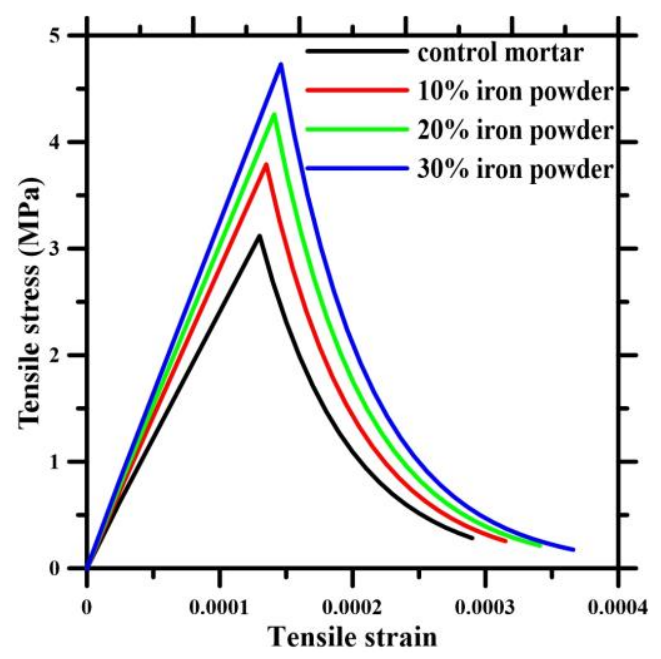

Figure 13: Simulated tensile constitutive response of control mortar as well as mortars containing iron powder-modified matrix

\subsubsection{Macro-scale fracture responses}

The macro-scale simulation of a three-point-bend test incorporates the material properties of the mortars, obtained from numerical homogenization, and performs the analysis using XFEM-based framework implementing CDP to obtain TPFM parameters. The notched beam model is shown in Figure 9 (c). Threepoint-bend model in ABAQUS ${ }^{\text {TM }}$ simulates a displacement controlled test. A mesh sensitivity study was performed and a mesh containing 1027 CPE4R elements provided converged solution. Under the 
application of center-point displacement, the crack initiates when the stress reaches the tensile strength beyond which the propagation of crack is governed by traction-separation law (defined by initial fracture energy $\left(\mathrm{G}_{f}\right)$, total fracture energy $\left(G_{\mathrm{F}}\right)$ and tensile strength of matrix $\left.\left(f_{t}\right)\right)$ coupled with CDP. The values for the CDP parameters $\beta, m, \gamma$ and $f$ are $38^{\circ}, 1,0.67$ and 1.12 respectively which are adopted from [66]. While these parameters are provided for concrete in [66], they are used in this study for mortars also, for lack of better experimental data on these parameters. Similar approach was successfully adopted in [94].

Figure 14 shows the load-CMOD responses obtained from XFEM simulation for control mortar as well as the mortars with varying iron powder content. As can be seen in the figure, the peak load increases with increase in iron powder content. The points P-1, P-2 and P-3 for the representative mortar containing 10\% iron powder correspond to $85 \%$ of peak load (pre-peak), $95 \%$ of peak load (post-peak) and a load that yields CMOD near ultimate failure respectively. The load-CMOD responses, thus obtained, are used later in this section to quantify TPFM parameters of these mortars.

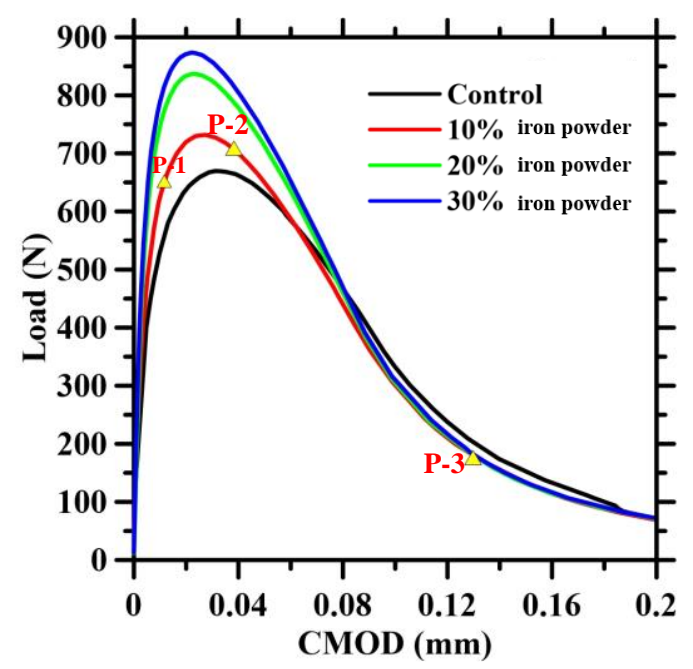

Figure 14: Simulated load-CMOD results for control and iron powder incorporated mortars with P1, P2 and $\mathrm{P} 3$ at $85 \%$ of peak load in pre-peak regime; P2 at $95 \%$ of peak load in post-peak regime; P3 at near ultimate failure

Figure 15 shows the maximum principal stress contours (for the representative mortar containing 10\% iron powder) at three different stages of the simulated load-CMOD response. These stages correspond to points P-1 (Figure 15(a)), P-2 (Figure 15(b)) and P-3 (Figure 15(c)) as shown in Figure 14. The figure corresponding to point $\mathrm{P} 1$ doesn't show crack formation since the maximum principal stress failure criterion is not met. On the other hand, the figure corresponding to point P2 show a single crack that have grown with a stress concentration at the tip of the crack. The figures corresponding to P3 depict that the crack have propagated almost completely leading to failure. 


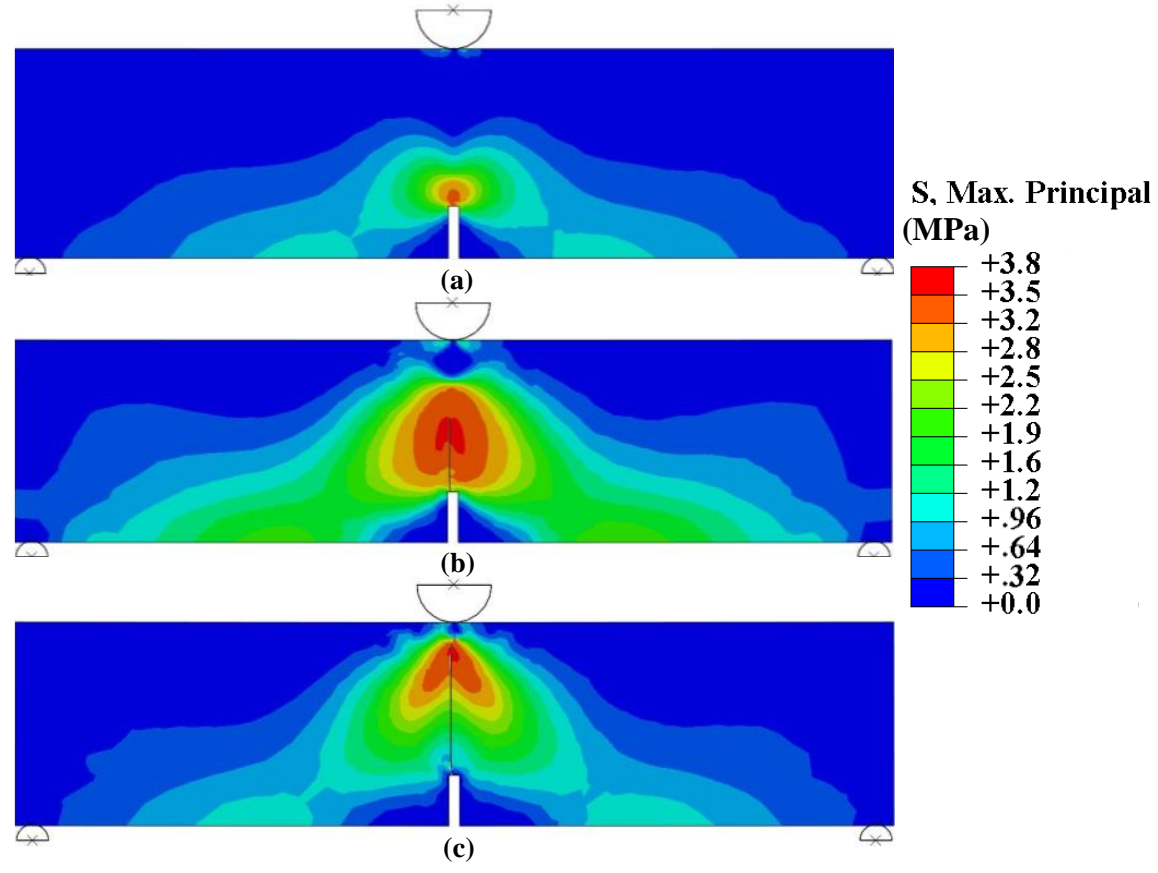

Figure 15. Maximum principal stress contours for mortar beams with 10\% iron powder (a) P1 (b) P2 and (c) P3

From the load-CMOD response and crack-extension values obtained from XFEM, TPFM parameters are obtained using equation 2(a) and 2(b) as explained in sub-section 3.3.2. Table 4 shows the simulated TPFM parameters along with those experimentally obtained from DIC.

Table 4. TPFM parameters for varying iron powder containing mortars obtained by DIC experiments and XFEM simulations

\begin{tabular}{|l|c|c|c|c|c|c|c|c|}
\hline \multicolumn{4}{|c|}{ Fracture Toughness $\left(\mathbf{K}_{\mathbf{I C}}\right)\left[\mathbf{M P a . m m}^{\mathbf{0 . 5}}\right.$ ] } & \multicolumn{3}{c|}{ Crack tip opening displacement, CTOD $_{\mathbf{c}}(\mathbf{m m})$} \\
\hline Iron Powder \% & 0 & 10 & 20 & 30 & 0 & 10 & 20 & 30 \\
\hline XFEM & 21.41 & 25.31 & 26.81 & 28.51 & 0.0013 & 0.0014 & 0.0016 & 0.0017 \\
\hline Experimental & 21.92 & 24.24 & 25.29 & 27.06 & 0.0012 & 0.0013 & $0.0014 \pm$ & 0.0018 \\
(DIC) & \pm 2.15 & \pm 1.85 & \pm 1.52 & \pm 1.61 & \pm 0.00018 & \pm 0.00017 & 0.00013 & \pm 0.00011 \\
\hline
\end{tabular}

The fracture parameters $\left(\mathrm{K}_{\mathrm{IC}}\right.$ and $\left.\mathrm{CTOD}_{\mathrm{C}}\right)$ obtained from multiscale numerical simulation are found to be in very good agreement with those directly obtained from DIC for control mortar as well as mortars with varying iron powder content signifying efficacy of the multiscale numerical simulation approach presented in this study. 


\section{CONCLUSION}

This study involves combined experimental and numerical evaluations to provide insight into the fracture response of waste iron powder-incorporated mortars. Experimental evaluations using CMOD-controlled three-point-bend test coupled with DIC showed superior flexural fracture response of modified cementitious systems when waste iron powder is used to replace cement. While experimental evaluations established beneficial impact of iron powder when added as cement-replacement (up to $30 \%$ by volume), the multiscale numerical approach, presented in this paper, is aimed towards development of a predictive tool that can help develop design strategies for efficient performance of these particulate-reinforced systems. The multiscale numerical simulation approach performs numerical homogenization at different length scales. The numerical homogenization approach incorporates interfacial debonding using CZMbased interface damage approach and implements isotropic damage in the matrix to obtain post-peak response. The homogenized constitutive response, thus obtained from numerical homogenization, serves as input to the macro-scale XFEM simulation of three-point-bend test on notched beams. The macro-model uses a maximum principal stress-based crack initiation criteria and implements bilinear traction-separation law coupled with CDP as crack propagation criteria to obtain $\mathrm{K}_{\mathrm{IC}}$ and $\mathrm{CTOD}_{\mathrm{c}}$ values for iron particulatereinforced mortars. The simulated values of $\mathrm{K}_{\mathrm{IC}}$ and $\mathrm{CTOD}_{\mathrm{c}}$ are found to be in good agreement with the experimental values obtained from DIC for varying dosage of iron powder signifying efficacy of the multiscale numerical simulation approach. Thus the multiscale numerical simulation framework, presented in this study, successfully links the material structure at different length scales to obtain macro-scale mechanical response of particulate-reinforced mortars facilitating microstructure-guided material design. Although the simulation approach is specifically applied in this paper towards particulate-reinforced mortars, it can also potentially provide efficient means to tailor the microstructure of a large class of inclusion-modified cementitious composites which needs further investigation.

\section{ACKNOWLEDGEMENT}

The authors gratefully acknowledge the support from College of Engineering (COE) and Department of Civil and Environmental Engineering at the University of Rhode Island (URI) towards this study.

\section{REFERENCE}

[1] J.-H. Xu, T. Fleiter, W. Eichhammer, Y. Fan, Energy consumption and CO2 emissions in China's cement industry: A perspective from LMDI decomposition analysis, Energy Policy. 50 (2012) 821832.

[2] J.S. Gregg, R.J. Andres, G. Marland, China: Emissions pattern of the world leader in $\mathrm{CO} 2$ emissions from fossil fuel consumption and cement production, Geophys. Res. Lett. 35 (2008).

[3] E. Worrell, L. Price, N. Martin, C. Hendriks, L.O. Meida, Carbon Dioxide Emissions from the Global Cement Industry, Annu. Rev. Energy Environ. 26 (2001) 303-329. 
[4] R.M. Andrew, Global CO 2 emissions from cement production, Earth Syst. Sci. Data KatlenburgLindau. 10 (2018) 195-217.

[5] S.P. Shah, S.E. Swartz, C. Ouyang, Fracture Mechanics of Concrete: Applications of Fracture Mechanics to Concrete, Rock and Other Quasi-Brittle Materials, John Wiley \& Sons, 1995.

[6] N. Banthia, M. Sappakittipakorn, Toughness enhancement in steel fiber reinforced concrete through fiber hybridization, Cem. Concr. Res. 37 (2007) 1366-1372.

[7] R. Snellings, G. Mertens, J. Elsen, Supplementary Cementitious Materials, Rev. Mineral. Geochem. 74 (2012) 211-278.

[8] B. Lothenbach, K. Scrivener, R.D. Hooton, Supplementary cementitious materials, Cem. Concr. Res. 41 (2011) 1244-1256.

[9] F. Pacheco-Torgal, J. Castro-Gomes, S. Jalali, Alkali-activated binders: A review. Part 2. About materials and binders manufacture, Constr. Build. Mater. 22 (2008) 1315-1322.

[10] F. Pacheco-Torgal, J. Castro-Gomes, S. Jalali, Alkali-activated binders: A review: Part 1. Historical background, terminology, reaction mechanisms and hydration products, Constr. Build. Mater. 22 (2008) 1305-1314.

[11] M.C.G. Juenger, F. Winnefeld, J.L. Provis, J.H. Ideker, Advances in alternative cementitious binders, Cem. Concr. Res. 41 (2011) 1232-1243.

[12] S. Das, B. Souliman, D. Stone, N. Neithalath, Synthesis and Properties of a Novel Structural Binder Utilizing the Chemistry of Iron Carbonation, ACS Appl. Mater. Interfaces. 6 (2014) 8295-8304. doi:10.1021/am5011145.

[13] S. Das, D. Stone, D. Convey, N. Neithalath, Pore- and micro-structural characterization of a novel structural binder based on iron carbonation, Mater. Charact. 98 (2014) 168-179. doi:10.1016/j.matchar.2014.10.025.

[14] S. Das, A. Hendrix, D. Stone, N. Neithalath, Flexural fracture response of a novel iron carbonate matrix - Glass fiber composite and its comparison to Portland cement-based composites, Constr. Build. Mater. 93 (2015) 360-370.

[15] B. Budiansky, J.C. Amazigo, A.G. Evans, Small-scale crack bridging and the fracture toughness of particulate-reinforced ceramics, J. Mech. Phys. Solids. 36 (1988) 167-187.

[16] R.O. Ritchie, Mechanisms of fatigue crack propagation in metals, ceramics and composites: Role of crack tip shielding, Mater. Sci. Eng. A. 103 (1988) 15-28.

[17] F.H. Gojny, M.H.G. Wichmann, U. Köpke, B. Fiedler, K. Schulte, Carbon nanotube-reinforced epoxy-composites: enhanced stiffness and fracture toughness at low nanotube content, Compos. Sci. Technol. 64 (2004) 2363-2371.

[18] S. Chandrasekaran, N. Sato, F. Tölle, R. Mülhaupt, B. Fiedler, K. Schulte, Fracture toughness and failure mechanism of graphene based epoxy composites, Compos. Sci. Technol. 97 (2014) 90-99.

[19] B.C. Kim, S.W. Park, D.G. Lee, Fracture toughness of the nano-particle reinforced epoxy composite, Compos. Struct. 86 (2008) 69-77.

[20] J. Cha, G.H. Jun, J.K. Park, J.C. Kim, H.J. Ryu, S.H. Hong, Improvement of modulus, strength and fracture toughness of CNT/Epoxy nanocomposites through the functionalization of carbon nanotubes, Compos. Part B Eng. 129 (2017) 169-179.

[21] D.J. Lloyd, Aspects of fracture in particulate reinforced metal matrix composites, Acta Metall. Mater. 39 (1991) 59-71.

[22] I.A. Ibrahim, F.A. Mohamed, E.J. Lavernia, Particulate reinforced metal matrix composites - a review, J. Mater. Sci. 26 (1991) 1137-1156.

[23] V.V. Krstic, P.S. Nicholson, R.G. Hoagland, Toughening of Glasses by Metallic Particles, J. Am. Ceram. Soc. 64 (1981) 499-504.

[24] R.D. Conner, H. Choi-Yim, W.L. Johnson, Mechanical properties of Zr57Nb5Al10Cu15.4Ni12.6 metallic glass matrix particulate composites, J. Mater. Res. 14 (1999) 3292-3297.

[25] Q.T. Nguyen, D.G. Baird, Preparation of polymer-clay nanocomposites and their properties, Adv. Polym. Technol. 25 (2006) 270-285. doi:10.1002/adv.20079. 
[26] D.W. Litchfield, D.G. Baird, The role of nanoclay in the generation of poly(ethylene terephthalate) fibers with improved modulus and tenacity, Polymer. 49 (2008) 5027-5036.

[27] J. Spanoudakis, R.J. Young, Crack propagation in a glass particle-filled epoxy resin, J. Mater. Sci. (1984) 473-486.

[28] F.F. Lange, Fracture Energy and Strength Behavior of a Sodium Borosilicate Glass-A12O3 Composite System, J. Am. Ceram. Soc. 54 (1971) 614-620.

[29] K. Holschemacher, T. Mueller, Y. Ribakov, Effect of steel fibres on mechanical properties of highstrength concrete, Mater. Des. 1980-2015. 31 (2010) 2604-2615.

[30] R.V. Balendran, F.P. Zhou, A. Nadeem, A.Y.T. Leung, Influence of steel fibres on strength and ductility of normal and lightweight high strength concrete, Build. Environ. 37 (2002) 1361-1367.

[31] A. Sivakumar, M. Santhanam, Mechanical properties of high strength concrete reinforced with metallic and non-metallic fibres, Cem. Concr. Compos. 29 (2007) 603-608.

[32] K. Chandramouli, P.R. Srinivasa, Strength properties of glass fibre concrete, ARPN J. Eng. Appl. Sci. 5 (2010) 6.

[33] H.A. Toutanji, T. El-Korchi, R.N. Katz, Strength and reliability of carbon-fiber-reinforced cement composites, Cem. Concr. Compos. 16 (1994) 15-21.

[34] H.A. Toutanji, T. El-Korchi, R.N. Katz, G.L. Leatherman, Behaviour of carbon fiber reinforced cement composites in direct tension, Cem. Concr. Res. 23 (1993) 618-626.

[35] V. Dey, R. Kachala, A. Bonakdar, B. Mobasher, Mechanical properties of micro and sub-micron wollastonite fibers in cementitious composites, Constr. Build. Mater. 82 (2015) 351-359. doi:10.1016/j.conbuildmat.2015.02.084.

[36] Dey Vikram, Kachala Robert, Bonakdar Amir, Neithalath Narayanan, Mobasher Barzin, Quantitative 2D Restrained Shrinkage Cracking of Cement Paste with Wollastonite Microfibers, J. Mater. Civ. Eng. 28 (2016) 4016082. doi:10.1061/(ASCE)MT.1943-5533.0001592.

[37] Y. Yao, F.A. Silva, M. Butler, V. Mechtcherine, B. Mobasher, Tension stiffening in textilereinforced concrete under high speed tensile loads, Cem. Concr. Compos. 64 (2015) 49-61. doi:10.1016/j.cemconcomp.2015.07.009.

[38] V. Dey, G. Zani, M. Colombo, M. Di Prisco, B. Mobasher, Flexural impact response of textilereinforced aerated concrete sandwich panels, Mater. Des. 86 (2015) 187-197. doi:10.1016/j.matdes.2015.07.004.

[39] M. Papachristoforou, I. Papayianni, Radiation shielding and mechanical properties of steel fiber reinforced concrete (SFRC) produced with EAF slag aggregates, Radiat. Phys. Chem. 149 (2018) $26-32$.

[40] Y.-C. Kan, K.-C. Pei, C.-L. Chang, Strength and fracture toughness of heavy concrete with various iron aggregate inclusions, Nucl. Eng. Des. 228 (2004) 119-127.

[41] Z.Z. Ismail, E.A. AL-Hashmi, Reuse of waste iron as a partial replacement of sand in concrete, Waste Manag. 28 (2008) 2048-2053.

[42] S. Das, D. Stone, B. Mobasher, N. Neithalath, Strain energy and process zone based fracture characterization of a novel iron carbonate binding material, Eng. Fract. Mech. 156 (2016) 1-15.

[43] S. Nayak, A. Kizilkanat, N. Neithalath, S. Das, Influence of Metallic Particulate Reinforcement on Fracture Behavior of Alkali Activated Slag Binders[Accepted], J. Mater. Civ. Eng. (2018).

[44] M.A. Sutton, J.J. Orteu, H. Schreier, Image Correlation for Shape, Motion and Deformation Measurements: Basic Concepts,Theory and Applications, Springer Science \& Business Media, 2009.

[45] S. Das, M. Aguayo, G. Sant, B. Mobasher, N. Neithalath, Fracture process zone and tensile behavior of blended binders containing limestone powder, Cem. Concr. Res. 73 (2015) 51-62.

[46] S. Das, M. Aguayo, V. Dey, R. Kachala, B. Mobasher, G. Sant, N. Neithalath, The fracture response of blended formulations containing limestone powder: Evaluations using two-parameter fracture model and digital image correlation, Cem. Concr. Compos. 53 (2014) 316-326. doi:10.1016/j.cemconcomp.2014.07.018. 
[47] T. Mori, K. Tanaka, Average stress in matrix and average elastic energy of materials with misfitting inclusions, Acta Metall. 21 (1973) 571-574. doi:10.1016/0001-6160(73)90064-3.

[48] M. Hori, S. Nemat-Nasser, Double-inclusion model and overall moduli of multi-phase composites, Mech. Mater. 14 (1993) 189-206. doi:10.1016/0167-6636(93)90066-Z.

[49] C.C. Yang, R. Huang, Double inclusion model for approximate elastic moduli of concrete material, Cem. Concr. Res. 26 (1996) 83-91. doi:10.1016/0008-8846(95)00196-4.

[50] S. Das, M. Aguayo, N. Kabay, B. Mobasher, G. Sant, N. Neithalath, Elucidating the influences of compliant microscale inclusions on the fracture behavior of cementitious composites, Cem. Concr. Compos. 94 (2018) 13-23.

[51] S. Das, M. Aguayo, S.D. Rajan, G. Sant, N. Neithalath, Microstructure-guided numerical simulations to predict the thermal performance of a hierarchical cement-based composite material, Cem. Concr. Compos. 87 (2018) 20-28.

[52] M. Aguayo, S. Das, A. Maroli, N. Kabay, J.C.E. Mertens, S.D. Rajan, G. Sant, N. Chawla, N. Neithalath, The influence of microencapsulated phase change material (PCM) characteristics on the microstructure and strength of cementitious composites: Experiments and finite element simulations, Cem. Concr. Compos. 73 (2016) 29-41.

[53] N. Chawla, K.K. Chawla, Microstructure-based modeling of the deformation behavior of particle reinforced metal matrix composites, J. Mater. Sci. 41 (2006) 913-925.

[54] E. Padilla, V. Jakkali, L. Jiang, N. Chawla, Quantifying the effect of porosity on the evolution of deformation and damage in Sn-based solder joints by X-ray microtomography and microstructurebased finite element modeling, Acta Mater. 60 (2012) 4017-4026.

[55] S. Das, A. Maroli, S.S. Singh, T. Stannard, X. Xiao, N. Chawla, N. Neithalath, A microstructureguided constitutive modeling approach for random heterogeneous materials: Application to structural binders, Comput. Mater. Sci. 119 (2016) 52-64.

[56] P. Grassl, D. Grégoire, L. Rojas Solano, G. Pijaudier-Cabot, Meso-scale modelling of the size effect on the fracture process zone of concrete, Int. J. Solids Struct. 49 (2012) 1818-1827.

[57] P. Grassl, M. Jirásek, Meso-scale approach to modelling the fracture process zone of concrete subjected to uniaxial tension, Int. J. Solids Struct. 47 (2010) 957-968.

[58] J.G.M. van Mier, Fracture Processes of Concrete, CRC Press, 2017. https://www.taylorfrancis.com/books/9781351447232 (accessed September 20, 2018).

[59] G. Alfano, E. Sacco, Combining interface damage and friction in a cohesive-zone model, Int. J. Numer. Methods Eng. 68 (2006) 542-582.

[60] M. Elices, C. Rocco, C. Roselló, Cohesive crack modelling of a simple concrete: Experimental and numerical results, Eng. Fract. Mech. 76 (2009) 1398-1410.

[61] J. Roesler, G.H. Paulino, K. Park, C. Gaedicke, Concrete fracture prediction using bilinear softening, Cem. Concr. Compos. 29 (2007) 300-312.

[62] J. Mazars, A description of micro- and macroscale damage of concrete structures, Eng. Fract. Mech. 25 (1986) 729-737.

[63] J. Mazars, G. Pijaudier-Cabot, Continuum Damage Theory-Application to concrete, J. Eng. Mech. 115 (1989).

[64] P. Wriggers, S.O. Moftah, Mesoscale models for concrete: Homogenisation and damage behaviour, Finite Elem. Anal. Des. 42 (2006) 623-636.

[65] S. Das, N. Neithalath, Microstructure-Guided Constitutive Modeling and Fracture Prediction of Cementitious Systems, in: IGCMAT, LA, 2016: p. 9.

[66] T. Jankowiak, T. Lodygowski, Identification of parameters of concrete damage plasticity constitutive model, Found. Civ. Environ. Eng. 6 (2005) 53-69.

[67] G.Z. Voyiadjis, Z.N. Taqieddin, P.I. Kattan, Anisotropic damage-plasticity model for concrete, Int. J. Plast. 24 (2008) 1946-1965.

[68] M. Krottenthaler, C. Schmid, J. Schaufler, K. Durst, M. Göken, A simple method for residual stress measurements in thin films by means of focused ion beam milling and digital image correlation, Surf. Coat. Technol. 215 (2013) 247-252. 
[69] Y. Yuan, J. Huang, X. Peng, C. Xiong, J. Fang, F. Yuan, Accurate displacement measurement via a self-adaptive digital image correlation method based on a weighted ZNSSD criterion, Opt. Lasers Eng. 52 (2014) 75-85.

[70] Vic-2D Reference Manual, (2009). http://www.correlatedsolutions.com/installs/Vic-2D-2009Manual.pdf.

[71] B. Mobasher, M. Bakhshi, C. Barsby, Backcalculation of residual tensile strength of regular and high performance fiber reinforced concrete from flexural tests, Constr. Build. Mater. 70 (2014) 243253.

[72] A. Hillerborg, Results of three comparative test series for determining the fracture energyG F of concrete, Mater. Struct. 18 (1985) 407-413.

[73] A. Hillerborg, The theoretical basis of a method to determine the fracture energyGFof concrete, Mater. Struct. 18 (1985) 291-296.

[74] Y. Jenq, S.P. Shah, Two parameter fracture model for concrete, J. Eng. Mech. 111 (1985) 12271241.

[75] A. Dakhane, S. Das, S. Kailas, N. Neithalath, Elucidating the Crack Resistance of Alkali-Activated Slag Mortars Using Coupled Fracture Tests and Image Correlation, J. Am. Ceram. Soc. 99 (2016) 273-280.

[76] E.E. Gdoutos, Fracture Mechanics: An Introduction, Springer Science \& Business Media, 2006.

[77] Soranakom C., Mobasher B., Closed-Form Solutions for Flexural Response of Fiber-Reinforced Concrete Beams, J. Eng. Mech. 133 (2007) 933-941. doi:10.1061/(ASCE)07339399(2007)133:8(933).

[78] O. Bernard, F.-J. Ulm, E. Lemarchand, A multiscale micromechanics-hydration model for the earlyage elastic properties of cement-based materials, Cem. Concr. Res. 33 (2003) 1293-1309.

[79] Zaoui André, Continuum Micromechanics: Survey, J. Eng. Mech. 128 (2002) 808-816.

[80] T. Wu, P. Wriggers, Multiscale diffusion-thermal-mechanical cohesive zone model for concrete, Comput. Mech. 55 (2015) 999-1016.

[81] S. Nayak, S. Das, A Microstructure-guided Numerical Approach to Evaluate Strain Sensing and Damage Detection Ability of Random Heterogeneous Self-sensing Materials: Application to a Smart Structural Material Containing Nano-engineered Interfaces[Accepted], Comput. Mater. Sci. (2018).

[82] B.D. Lubachevsky, F.H. Stillinger, E.N. Pinson, Disks vs. spheres: Contrasting properties of random packings, J. Stat. Phys. 64 (1991) 501-524.

[83] B.D. Lubachevsky, F.H. Stillinger, Geometric properties of random disk packings, J. Stat. Phys. 60 (1990) 561-583.

[84] O. van der Sluis, P.J.G. Schreurs, W.A.M. Brekelmans, H.E.H. Meijer, Overall behaviour of heterogeneous elastoviscoplastic materials: effect of microstructural modelling, Mech. Mater. 32 (2000) 449-462.

[85] S. Das, P. Yang, S.S. Singh, J.C.E. Mertens, X. Xiao, N. Chawla, N. Neithalath, Effective properties of a fly ash geopolymer: Synergistic application of X-ray synchrotron tomography, nanoindentation, and homogenization models, Cem. Concr. Res. 78 (2015) 252-262.

[86] H.A. Meier, E. Kuhl, P. Steinmann, A note on the generation of periodic granular microstructures based on grain size distributions, Int. J. Numer. Anal. Methods Geomech. 32 (2008) 509-522.

[87] J. Roesler, G.H. Paulino, K. Park, Concrete fracture prediction using bilinear softening ScienceDirect, Cem. Concr. Compos. 29 (2007) 300-312.

[88] M. Kurumatani, K. Terada, J. Kato, T. Kyoya, K. Kashiyama, An isotropic damage model based on fracture mechanics for concrete, Eng. Fract. Mech. 155 (2016) 49-66.

[89] M. Hain, P. Wriggers, Numerical homogenization of hardened cement paste, Comput. Mech. 42 (2008) 197-212.

[90] P. Yang, S. Chowdhury, N. Neithalath, Strain sensing ability of metallic particulate reinforced cementitious composites: Experiments and microstructure-guided finite element modeling, Cem. Concr. Compos. 90 (2018) 225-234. 
[91] O. Y1lmaz, J.-F. Molinari A mesoscale fracture model for concrete, Cem. Concr. Res. 97 (2017) 8494.

[92] S. Da, J. Němeček, P. Štemberk, Application of multiscale elastic homogenization based on nanoindentation for high performance concrete, Adv. Eng. Softw. 62-63 (2013) 109-118.

[93] A. Hillerborg, The theoretical basis of a method to determine the fracture energyGFof concrete, Mater. Struct. 18 (1985) 291-296.

[94] S. Das, C. Hoffarth, B. Ren, B. Spencer, G. Sant, S.D. Rajan, N. Neithalath, Simulating the Fracture of Notched Mortar Beams through Extended Finite Element Method (XFEM) and Peridynamics, J. Eng. Mech. In press DOI 10.1061/(ASCE)EM.1943-7889.0001628 (2018). 